\title{
Impact Analysis of Window-Wall Ratio on Heating and Cooling Energy Consumption of Residential Buildings in Hot Summer and Cold Winter Zone in China
}

\author{
Qiaoxia Yang, ${ }^{1,2}$ Meng Liu, ${ }^{1,2,3}$ Chang Shu, ${ }^{4}$ Daniel Mmereki, ${ }^{1}$ \\ Md. Uzzal Hossain, ${ }^{5}$ and Xiang Zhan ${ }^{6}$ \\ ${ }^{1}$ Faculty of Urban Construction and Environmental Engineering, Chongqing University, Chongqing 400045, China \\ ${ }^{2}$ Key Laboratory of Three Gorges Reservoir Region's Eco-Environment, Ministry of Education, Chongqing University, \\ Chongqing 400045, China \\ ${ }^{3}$ National Centre for International Research of Low-Carbon and Green Buildings, Chongqing University, Chongqing 400045, China \\ ${ }^{4}$ Institute of Refrigeration and Thermal Engineering, School of Mechanical Engineering, Tongji University, Shanghai 200092, China \\ ${ }^{5}$ Department of Civil and Environmental Engineering, The Hong Kong Polytechnic University, Kowloon, Hong Kong \\ ${ }^{6}$ CMCU Engineering Co. Ltd., Chongqing 400039, China
}

Correspondence should be addressed to Meng Liu; liumeng2033@126.com

Received 14 December 2014; Revised 23 April 2015; Accepted 30 April 2015

Academic Editor: Guy Lauriat

Copyright (C) 2015 Qiaoxia Yang et al. This is an open access article distributed under the Creative Commons Attribution License, which permits unrestricted use, distribution, and reproduction in any medium, provided the original work is properly cited.

\begin{abstract}
In order to assess the optimal window-wall ratio and the proper glazing type in different air conditioning system operation modes of residential buildings for each orientation in three typical cities in hot summer and cold winter zone: Chongqing, Shanghai, and Wuhan simulation models were built and analyzed using Designer's Simulation Toolkit (DeST). The study analyzed the variation of annual heating energy demand, annual cooling energy demand, and the annual total energy consumption in different conditions, including different orientations, patterns of utilization of air conditioning system, window-wall ratio, and types of windows. The results show that the total energy consumption increased when the window-wall ratio is also increased. It appears more obvious when the window orientation is east or west. Furthermore, in terms of energy efficiency, low-emissivity (Low-E) glass performs better than hollow glass. From this study, it can be concluded that the influence and sensitivity of window-wall ratio on the total energy consumption are related to the operation mode of air conditioning system, the orientation of outside window, and the glazing types of window. The influence of the factors can be regarded as reference mode for the window-wall ratio when designing residential buildings.
\end{abstract}

\section{Introduction}

Energy use in buildings accounts for a large percentage of total energy consumption worldwide, which leads to increasing $\mathrm{CO}_{2}$ emission into the atmosphere. Studies in Europe on energy consumption have shown that buildings are responsible for $40 \%$ of energy end use and 30\% of $\mathrm{CO}_{2}$ emission [1]. Windows have a significant influence on building energy performance. The proper design of windows can greatly reduce energy consumption in buildings. In order to encourage the development and the appropriate use of high performance glazing and windows, many window energy rating systems (WERS) have been developed in different countries.

Window-wall ratio is the specific value of the area of the window and that of the room façade. Unit area of room façade indicates the area enclosed by the room height and the standard width of the bay [2]. The natural lighting performance is better when the window-wall ratio increases. However, windows also play a critical role in terms of building thermal insulation which needs to be clearly considered. 
Many studies have focused on the relationship between window-wall ratio and building energy consumption. Hou and $\mathrm{Fu}[3]$ studied the relationship between the windowwall ratio in hot summer and cold winter zone and the power consumption of air conditioning. Jian and Jiang [4] considered the effect of window-wall ratio on the building yearly heating energy consumption, yearly air conditioning energy consumption, and total annual energy consumption for different orientations in residential buildings in Shanghai. Feng and Yang [5] analyzed how different solar radiations influence the thermal process of windows. Furthermore, they presented the design principles of window-wall ratios on building energy efficiency in the hot summer and cold winter zone. Wang et al. [6] explored the energy saving effect of building envelope in summer through experiments and simulations. As a result of advancement of computational capability, the optimum window size and types to minimize energy consumption of buildings have been explored using computer simulation. Inanici and Demirbilek [7] analyzed the south window size and the building aspect ratio to minimize heating and cooling loads. Li et al. [8] simulated the annual air conditioning energy consumption of a typical residential building in Guangzhou using the energy consumption simulation software DeST-h, to study the impact of window-wall ratio on the energy consumption in natural and mechanical operation modes.

Zhou et al. [9] observed a low energy consumption office building in the northern China to analyze the cooling, heating, and lighting energy consumption considering each of the orientations of the building under the lighting control or no lighting control condition. Yu et al. [10] conducted a study on the HVAC system of the office building in different air conditioning modes with different orientations and window-wall ratio. They also made conclusion on how these factors impact on energy consumption. Goia et al. [11] investigated the optimum configuration of a façade module for office buildings. They observed that the north-exposed façade is the one that may suffer the most when a wrong configuration is adopted, while the south-exposed façade is the one where the influence of window-wall ratio is the lowest. The minimum total primary energy demand is always achieved when window-wall ratio is in the range of 35$45 \%$. Lee et al. [12] investigated the optimum annual heating, cooling, and lighting energy consumption by applying different types and properties of window systems in a building envelope. Therefore, using building simulation modeling, various window properties such as $U$-value, solar heat gain coefficient (SHGC), and visible transmittance are evaluated with different window-wall ratios and orientations in five typical Asian climatic zones: Manila, Taipei, Shanghai, Seoul, and Sapporo. It was observed that the relative window size must be minimized. Concerning the positioning of windows, for Manila and Taipei, placement of a window system on the north orientation offers the highest advantage for total energy savings, followed by the south, west, and east orientation, while in Shanghai, Seoul, and Sapporo, the south orientation has the greatest advantage for total energy savings, followed by the north, west, and east orientation. Kim et al. [13] have confirmed that the variation of the window elements such as the orientation, window-wall ratio, SHGC, and $U$-value affects energy consumption.

Al-Homoud [14] carried out an optimization study on building design variables in order to minimize annual energy consumption. In this research, it was observed that minimum glass area at a proportion of $15 \%$ was the best except the cold climate where larger glass area was required to use solar gain for heating. Kontoleon and Bikas [15] investigated the optimum glazed openings percentage from the viewpoint of the indoor temperature and the energy consumption of the supply system. Johnson et al. [16] examined the economically optimum window size and orientation. They concluded that the glass to wall ratio of less than $20 \%$ resulted in the minimum life-cycle cost. In addition, the north orientation was preferred for large glass to wall ratios. These studies have shown that large window size may result in the increase of a cooling load, while it causes the decrease of a heating load because of the enhanced solar gain. Su and Zhang [17] analyzed the environmental impacts of each process of a typical office building in Shanghai over the entire life cycle and found a proper value for window-wall ratio of different orientations and window materials by comparing the results of different scenarios. Tian et al. [18] presented first WERS for the window energy evaluation of typical office buildings and observed a typical office building in Hong Kong as an example to demonstrate how WERS in a particular location can be developed and how well the model can work. Ochoa et al. [19] carried out a research to determine the suitability of combined optimization criteria on window sizing procedures for low energy consumption with high visual comfort and performance.

Most of the previous research investigations only considered the whole building. Specific room function and different operation modes were not considered. However, different functions of the room or different usage habits of the room for the same function may result in a great difference in terms of the operation mode of the air conditioning systems, thus leading to the difference in the yearly heating load, cooling load, and air conditioning energy consumption.

Due to factors such as locations and orientations and heat transfer resistance of the windows, window-wall ratio impacts on the building energy consumption, and building energy consumption differs. For existing high-rise residential buildings of the city, the window-wall ratios of kitchens, bathroom, and living room are relatively stable while the window-wall ratios of bedrooms may differ considerably. In order to study the law of the impact of different windowwall ratios, operation modes of the air conditioning systems, orientations of the external windows, and the values of heat transfer resistance of the windows on the heating load, cooling load, and air conditioning energy consumption of bedrooms, the present study was carried out in typical cities in hot summer and cold winter zone in China. This was done to carry out analysis on how windows wall ratio impacts on heating, cooling energy consumption, and total energy 
consumption of the residential building based on the classic architectural plane form.

\section{Methodology}

2.1. Designer's Simulation Toolkit. The present study conducts an annual hourly dynamic simulation of the energy consumed by a typical residential building using Designer's Simulation Toolkit (DeST) software (developed by Tsinghua University, Beijing, China) [20].

DeST is composed of multiple separate modules. The structure diagram of DeST is presented in Figure 1. These modules include building analysis and simulation (BAS), air handing unit (AHU), combined plant simulation (CPS), and duct network analysis (DNA). It can carry out economic analysis model of the design objective and simulate accurate results in different design stages. In addition, natural lighting (lighting), natural ventilation (Ventplus), and shadow (B Shadow) modules can be calculated after modeling and can be used as input conditions of building analysis and simulation (BAS).

Meteorological parameters which influence the building thermal process mainly include air temperature, air humidity, solar radiation, wind speed and direction, and sky temperature. DeST established a meteorological model which can generate annual hourly meteorological data by the actual measured daily meteorological data. The fundamental data of the model comes from the actual measured daily meteorological data including air temperature, air humidity, solar radiation, wind speed and direction, insolation duration, and atmospheric pressure in 194 meteorological stations for about 50 years since the meteorological stations were built. According to the method of selecting typical year in air conditioning load calculation, the representative year such as typical meteorological year, highest temperature year, lowest temperature year, maximum solar radiation year, and minimum solar radiation year is selected at first. Based on the daily variation regularity of meteorological parameters, the hourly meteorological data including air temperature, air humidity, direct solar radiation, diffuse solar radiation, wind speed and direction and the sky temperature is generated by simulation. And the fundamental data of the typical meteorological year is used as fundamental data for annual simulation of DeST.

\subsection{Radiation Transmittance Model and Transfer Model of} DeST. Figure 2 provides the physical model of building thermal process simulation. The figure shows that there are many factors affecting the building indoor thermal environment, and solar radiation is an important external disturbance. The following content presents a detailed introduction of radiation transmittance model and transfer model for transparent elements of DeST.

Figure 3 provides the energy balance of medium layers. The entirety made up of windows, glass curtain wall and its accompanying sunshade component such as curtains is called

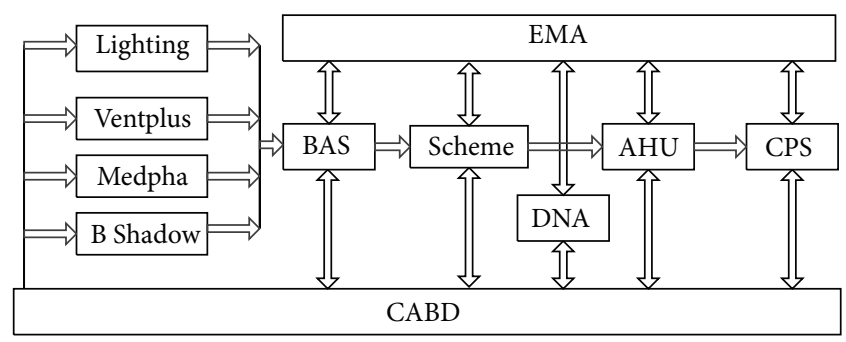

FIgURE 1: The structure diagram of DeST.

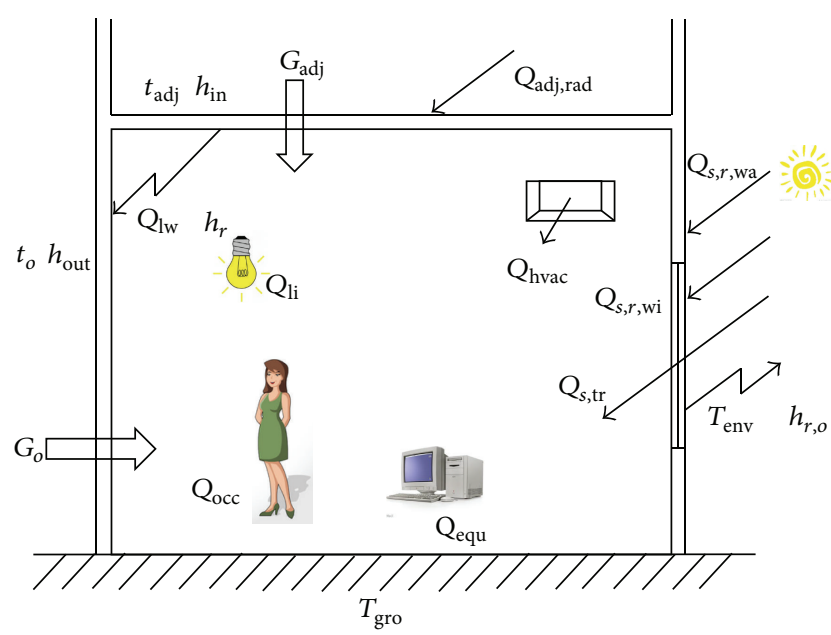

Figure 2: Physical model of building thermal process simulation.

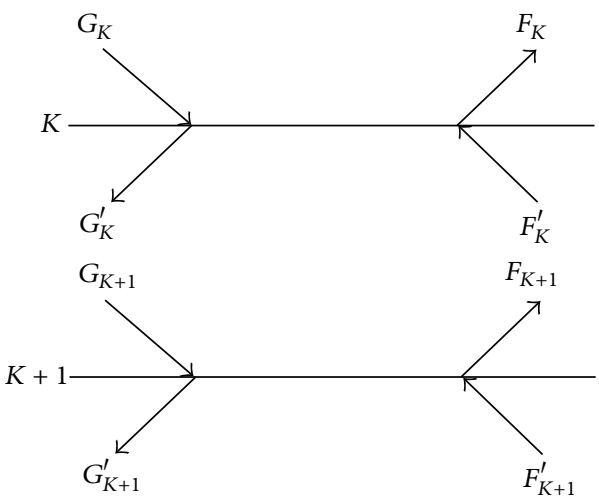

FIGURE 3: Energy balance of medium layers.

fenestration. Formula (1) is the recursive formula of each interface's effective transmittance in fenestration:

$$
\begin{aligned}
& \alpha_{K}=\frac{G_{K}^{\prime}}{G_{K}}, \\
& \beta_{K}=\frac{F_{K}}{G_{K}}, \\
& \beta_{K}^{\prime}=\frac{F_{K}^{\prime}}{G_{K}^{\prime}},
\end{aligned}
$$




$$
\begin{aligned}
\alpha_{K} & =\frac{1-\rho_{K}}{1-\rho_{K} \beta_{K}^{\prime}}, \\
\beta_{K} & =1-\alpha_{K}\left(1-\beta_{K}^{\prime}\right), \\
\beta_{K}^{\prime} & =\beta_{K+1} \cdot \tau_{a, K \rightarrow K+1}^{2}, \\
\tau_{a, K \rightarrow K+1} & =\frac{G_{K+1}}{G_{K}^{\prime}}, \\
\tau_{a, K \rightarrow K+1} & =\frac{F_{K}^{\prime}}{F_{K+1}} .
\end{aligned}
$$

Total transmittance of fenestration can be calculated by

$$
\begin{aligned}
\tau^{(N)} & =\frac{G_{N+1}}{G_{1}} \\
& =\frac{G_{N+1}}{G_{N}^{\prime}} \cdot \frac{G_{N}^{\prime}}{G_{N}} \cdot \frac{G_{N}}{G_{N-1}^{\prime}} \cdot \frac{G_{N-1}^{\prime}}{G_{N-1}} \ldots \cdot \frac{G_{2}}{G_{1}^{\prime}} \cdot \frac{G_{1}^{\prime}}{G_{1}} \\
& =\prod_{K=1}^{N} \alpha_{K} \cdot \prod_{K=1}^{N} \tau_{a, K \rightarrow K+1} .
\end{aligned}
$$

Absorbed solar radiation of a medium layer of fenestration can be calculated by

$$
\begin{aligned}
\zeta(K, K+1) & =\frac{Q_{K \rightarrow K+1}}{G_{1}}=\frac{Q_{K \rightarrow K+1}}{G_{K}} \cdot \frac{G_{K}}{G_{1}} \\
& =\zeta_{K \rightarrow K+1} \cdot \prod_{i=1}^{K-1}\left(\alpha_{i} \tau_{a, i \rightarrow i+1}\right), \\
\zeta_{K \rightarrow K+1} & =\frac{Q_{K \rightarrow K+1}}{G_{K}} .
\end{aligned}
$$

When light is flying from the refractive index medium for $n_{1}$ to the refractive index medium for $n_{2}$ with angle of incidence $\theta_{1}$ and angle of reflection $\theta_{2}$, reflectance of different mediums' adjacent interface can be calculated by the following according to Fresnel law [21]:

$$
\begin{aligned}
& \rho=\frac{1}{2}\left[\frac{\sin ^{2}\left(\theta_{2}-\theta_{1}\right)}{\sin ^{2}\left(\theta_{2}+\theta_{1}\right)}+\frac{\tan ^{2}\left(\theta_{2}-\theta_{1}\right)}{\tan ^{2}\left(\theta_{2}+\theta_{1}\right)}, \theta_{1} \geq 30^{\circ}\right], \\
& \rho=\left[\frac{n_{1}-n_{2}}{n_{1}+n_{2}}\right]^{2} .
\end{aligned}
$$

Based on the calculation of solar radiant heat transmittance and absorption of fenestration, thermal transfer model of window can be developed. An example of glass with 3 layers which is shown in Figure 4 is used to explain how the thermal transfer model of window is built. The following formula is

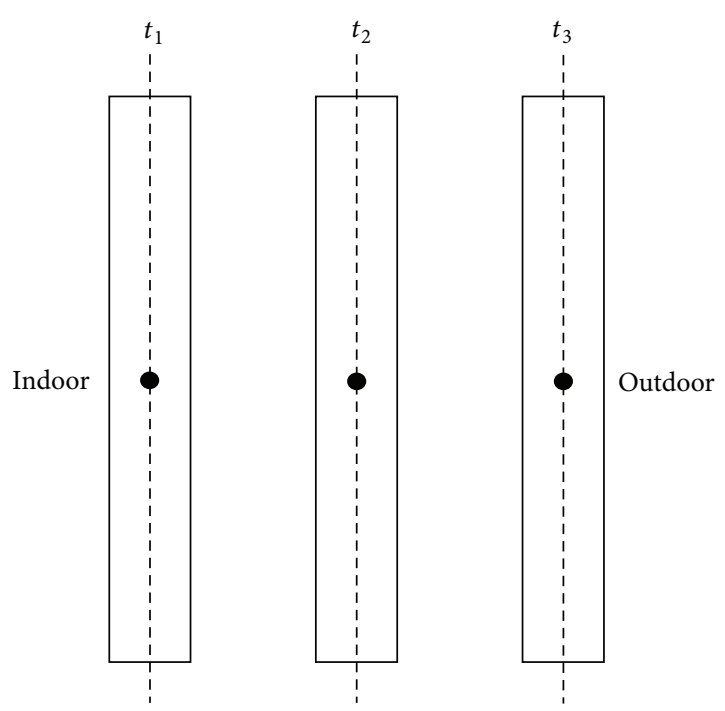

FIGURE 4: Nodal temperature of glass with 3 layers.

the thermal balance equations of inner, middle, and outer layer of window:

$$
\begin{aligned}
& c_{p 1} \rho_{1} \Delta x_{1} \frac{d t_{1}}{d \tau} \\
&= h_{1}\left(t_{1, a}-t_{1}\right) \\
&+\sum_{j} h_{r 1, j}\left(t_{1, j}-t_{1}\right)+h_{2,1}\left(t_{2}-t_{1}\right)+q_{1}+q_{1, \mathrm{rad}}, \\
& c_{p 2} \rho_{2} \Delta x_{2} \frac{d t_{2}}{d \tau}=h_{1,2}\left(t_{1}-t_{2}\right)+h_{3,2}\left(t_{3}-t_{2}\right)+q_{2}, \\
& c_{p 3} \rho_{3} \Delta x_{3} \frac{d t_{3}}{d \tau} \\
&=h_{3}\left(t_{3, a}-t_{3}\right) \\
& \quad+\sum_{j} h_{r 3, j}\left(t_{3, j}-t_{3}\right)+h_{2,3}\left(t_{2}-t_{3}\right)+q_{3}+q_{3, \mathrm{rad}}, \\
& h_{i, j}=\frac{1}{R_{i, j, \mathrm{air}}}+\frac{1}{R_{i, j, \mathrm{lvr}}}, \\
& R_{i, j \mathrm{lvr}} \\
&=\frac{1 / \varepsilon_{i}+1 / \varepsilon_{j}-1}{5.67 \times 10^{-8} \mathrm{~W} /\left(\mathrm{m}^{2} \cdot \mathrm{K}^{4}\right)\left(T_{i}^{2}+T_{j}^{2}\right)\left(T_{i}+T_{j}\right)} .
\end{aligned}
$$

$q_{1}, q_{2}$, and $q_{3}$ in thermal balance equations of each window layer can be obtained through solar radiation calculation of fenestration. Comprehensive heat transfer coefficient between two adjacent glass surfaces can be calculated by formula (6) [22]. 


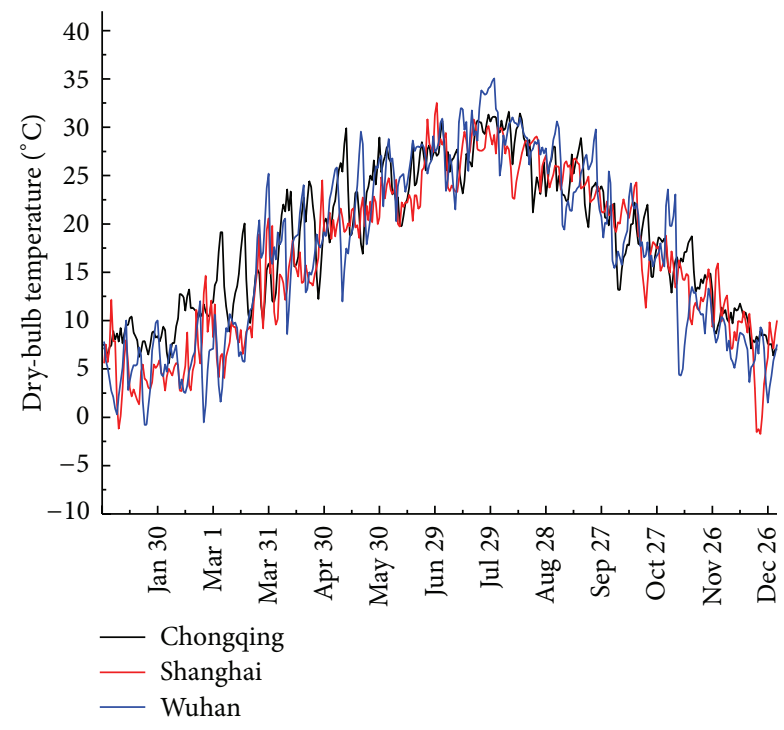

FIgUre 5: Annual daily dry-bulb temperature in Chongqing, Shanghai, and Wuhan.

\section{Meteorological Data}

China's topography is varied and complicated. Because of the different geographical conditions, climate in different zone has great disparity. In order to meet the different requirements on building in different climate conditions, China was divided into severe cold zone, cold zone, hot summer and cold winter zone, hot summer and warm winter zone, and temperate zone from the perspective of building thermal design by "Thermal Design Code for Civil Building" (GB50176-93) [23]. In order to assess the optimal windowwall ratio and the proper glazing type in different air conditioning system operation modes of residential buildings for each orientation in hot summer and cold winter zone, model in three typical cities Chongqing, Shanghai, and Wuhan is built and analyzed.

The meteorological data for Chongqing, Shanghai, and Wuhan during a typical meteorological year were calculated using DeST based on multiple years' meteorological data from the three cities. Figure 5 provides the daily dry-bulb temperature for a year. In Chongqing, the hottest month was July with a daily maximum temperature of $36.6^{\circ} \mathrm{C}$ and the coldest month was January with a daily minimum temperature of $3.4^{\circ} \mathrm{C}$. In Shanghai, the hottest month was July with a daily maximum temperature of $35.2^{\circ} \mathrm{C}$ and the coldest month was January with a daily minimum temperature of $-4.2^{\circ} \mathrm{C}$ while in Wuhan the hottest month was July with a daily maximum temperature of $38.8^{\circ} \mathrm{C}$ and the coldest month was January with a daily minimum temperature of $-3.9^{\circ} \mathrm{C}$.

Hourly total solar radiation and annual direct solar radiation distribution in Chongqing, Shanghai, and Wuhan were presented in Figures 6 and 7.

\section{Model Building}

All simulation stages in a DeST are performed on the user interface developed by AutoCAD. A model must first be
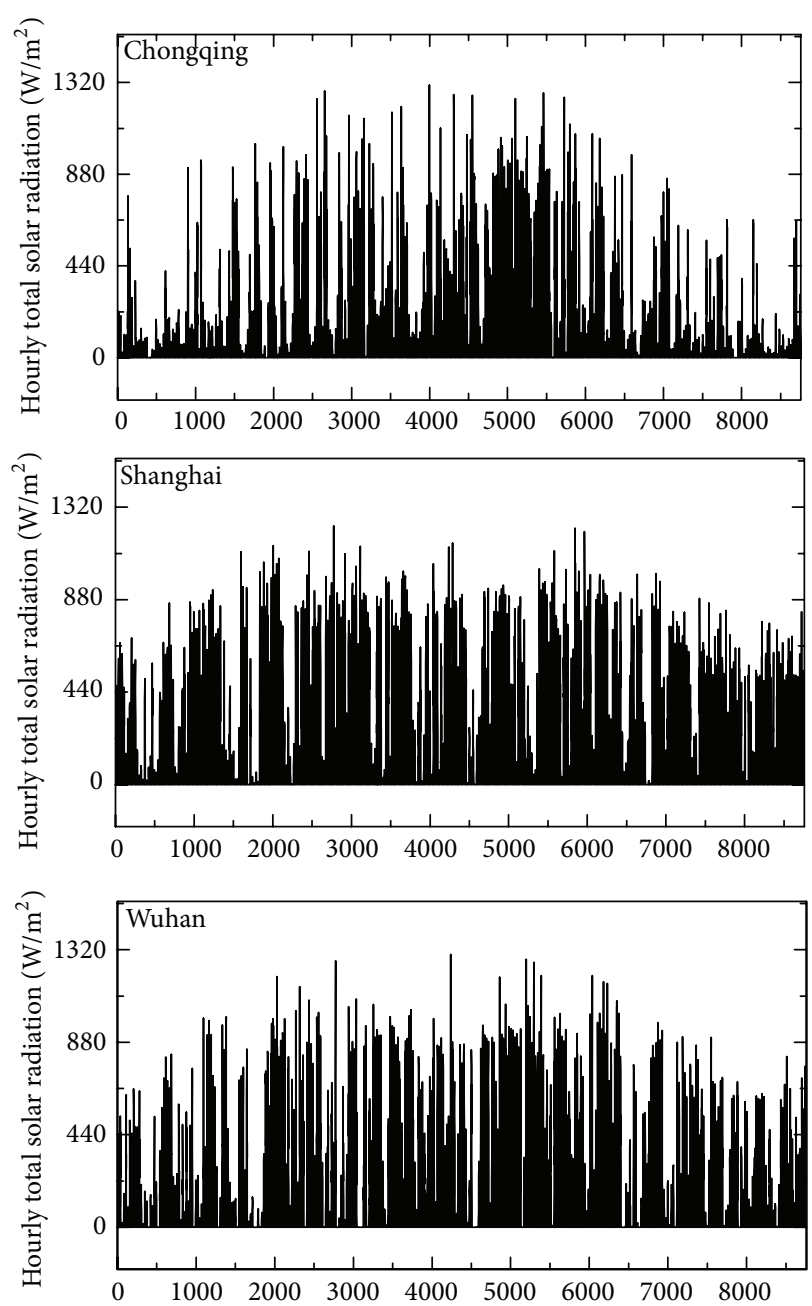

FIGURE 6: Hourly total solar radiation in Chongqing, Shanghai, and Wuhan.

built to simulate a building's energy consumption. Using the working architectural drawing of the building targeted for simulation, the external and internal walls are input into the DeST according to the size and the structure of the building. The doors and windows are then added. The topological structure of the building is established with all model parameters as close to the actual situation as possible.

4.1. Building Description and Parameters. The building considered in this study is a 6-floor traditional block and has a building area of $2648 \mathrm{~m}^{2}$. The shape coefficient of the building is 0.27 . There are 4 units in a floor, each with two bedrooms, one hall, one kitchen, and one toilet, shown in Figure 8. The orientation of the building is north and south with the storey height of $3.0 \mathrm{~m}$. The area of each unit is $86 \mathrm{~m}^{2}$ and the area of master bedroom is $22 \mathrm{~m}^{2}$. Simulated building model in DeST is presented in Figure 9. The air source heat pump is adopted as the cooling and heating requirement. The configurations of the building are described in Tables 1-4. The building envelop parameters satisfy the demand in Design Standard for Energy Efficiency of Residential Buildings in Hot Summer and Cold 


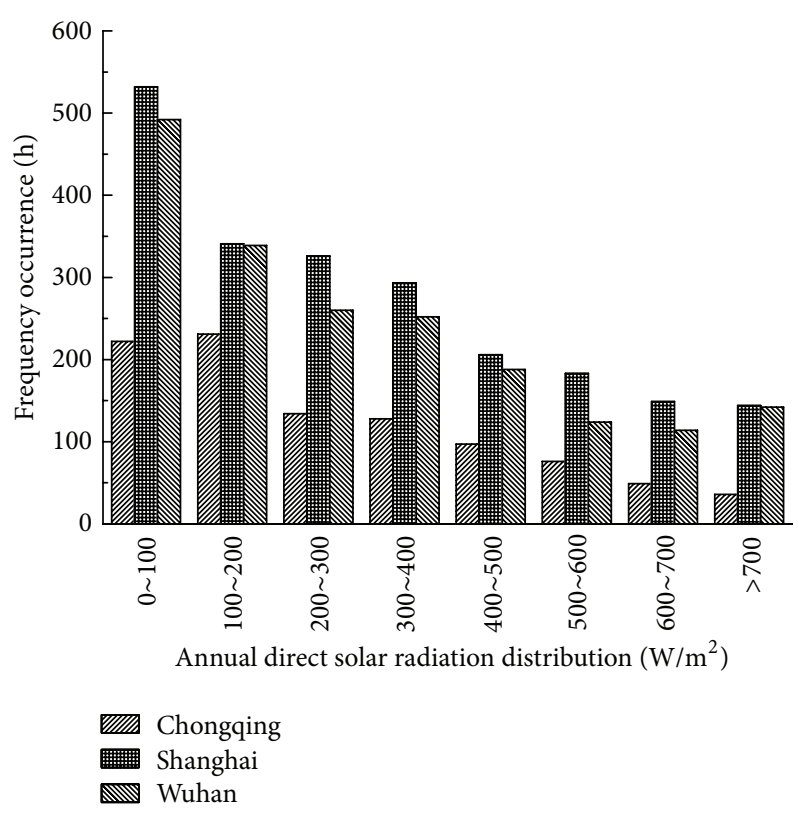

FIGURE 7: Annual direct solar radiation distribution in Chongqing, Shanghai, and Wuhan.

TABLE 1: Components and thermal performance of the building envelope.

\begin{tabular}{lcc}
\hline $\begin{array}{l}\text { Building } \\
\text { envelope }\end{array}$ & Building envelope components & $\begin{array}{c}\text { Heat transfer } \\
\text { coefficients } \\
\left(\mathrm{W} /\left(\mathrm{m}^{2} \cdot \mathrm{K}\right)\right)\end{array}$ \\
\hline $\begin{array}{l}\text { External } \\
\text { walls }\end{array}$ & $\begin{array}{c}20 \mathrm{~mm} \text { lime mortar }+150 \mathrm{~mm} \\
\text { porous concrete }+20 \mathrm{~mm} \mathrm{lime} \\
\text { mortar }\end{array}$ & 0.987 \\
\hline \multicolumn{3}{c}{$\begin{array}{c}20 \mathrm{~mm} \text { lime mortar }+200 \mathrm{~mm} \\
\text { porous concrete }+130 \mathrm{~mm} \\
\text { reinforced concrete }+15 \mathrm{~mm} \mathrm{lime} \\
\text { mortar }\end{array}$} \\
\hline
\end{tabular}

Winter Zone and some relevant local standards [2]. EER and $\mathrm{COP}$ values in Table 4 refer to actual operation conditions.

4.2. Operation Conditions. In order to explore the impact of window-wall ratio of bedrooms, operation modes of the HVAC systems, types of external windows, and the orientations of the windows on energy consumption, the simulation of the whole building was conducted. The operation mode of HVAC system was denoted by B1 B3; the type of external window was denoted by $\mathrm{C} 1$ and $\mathrm{C} 2$. The configurations of the operation modes and window-wall ratios are listed in Table 5. Operation mode B1 refers to the condition that the air conditioner is operating only when someone is sleeping. Operation mode $\mathrm{B} 2$ refers to the condition that the air conditioner is operating when someone is at home: close the air conditioner after getting up at 7:00 in the morning and go to work; operate the air conditioner for one hour during lunch break; come back home from work and operate the air conditioner of the bedroom immediately. Operation mode B3 refers to the condition that air conditioner is operating all day. This is because part of the families have the elderly at home, and the air conditioner is operating all day in summer and winter with consideration about the elderly's thermal comfort. The operation schedules of occupant, lighting, equipment, and air conditioning in bedroom are presented in Figures 10 and 11 (in air conditioning schedule, "1" on $y$-axis stands for "ON" status for air conditioning system while "0" stands for "OFF" status). The simulation period was 1 year.

\section{Results and Discussion}

A building model was established in DeST to simulate the annual energy consumption patterns of three cities of hot summer and cold winter zone: Chongqing, Shanghai, and Wuhan. The annual heating energy demand, annual cooling energy demand, and power consumption were calculated. The study analyzed the changing rule of the annual heating energy demand and annual cooling energy demand of the HVAC systems as well as the total energy consumption when the window-wall ratio changes according to the different window orientation, different types of glazing, and the different air conditioning operation modes.

5.1. Common Results for the Three Cities. The effects of window-wall ratio on annual heating energy demand, annual cooling energy demand, and total energy consumption in Chongqing, Shanghai, and Wuhan are presented in Figures 12-17. Some similarities can be obtained from these figures:

(1) The annual heating energy demand, annual cooling energy demand, and total energy consumption, respectively, change in similar pattern with the window-wall ratio in different operation modes.

(2) The windows facing east and west faces have a greater effect on energy consumption in comparison with the ones facing north and south; therefore, reducing the window-wall ratio would be more effective for the windows facing east and west than those facing south and north.

(3) The rate of change in annual cooling energy demand and total energy consumption decreases when the type of external window changes from hollow glass to Low- $E$ glass. As a result, the energy efficiency performance of Low- $E$ glass is better than hollow glass. It indicates that reducing window-wall ratio would be more effective when hollow glass is applied.

5.2. Differences in Results among the Three Cities. Except for the common results in the three cities, there are also many differences among them, especially for annual heating energy demand. The differences are outlined as follows:

(1) In Chongqing, annual heating energy demand, annual cooling energy demand, and total energy consumption increase in an almost linear pattern with the increase of window-wall ratio. However, in Shanghai and Wuhan, annual heating energy demand is stable with the increase in window-wall ratio, 


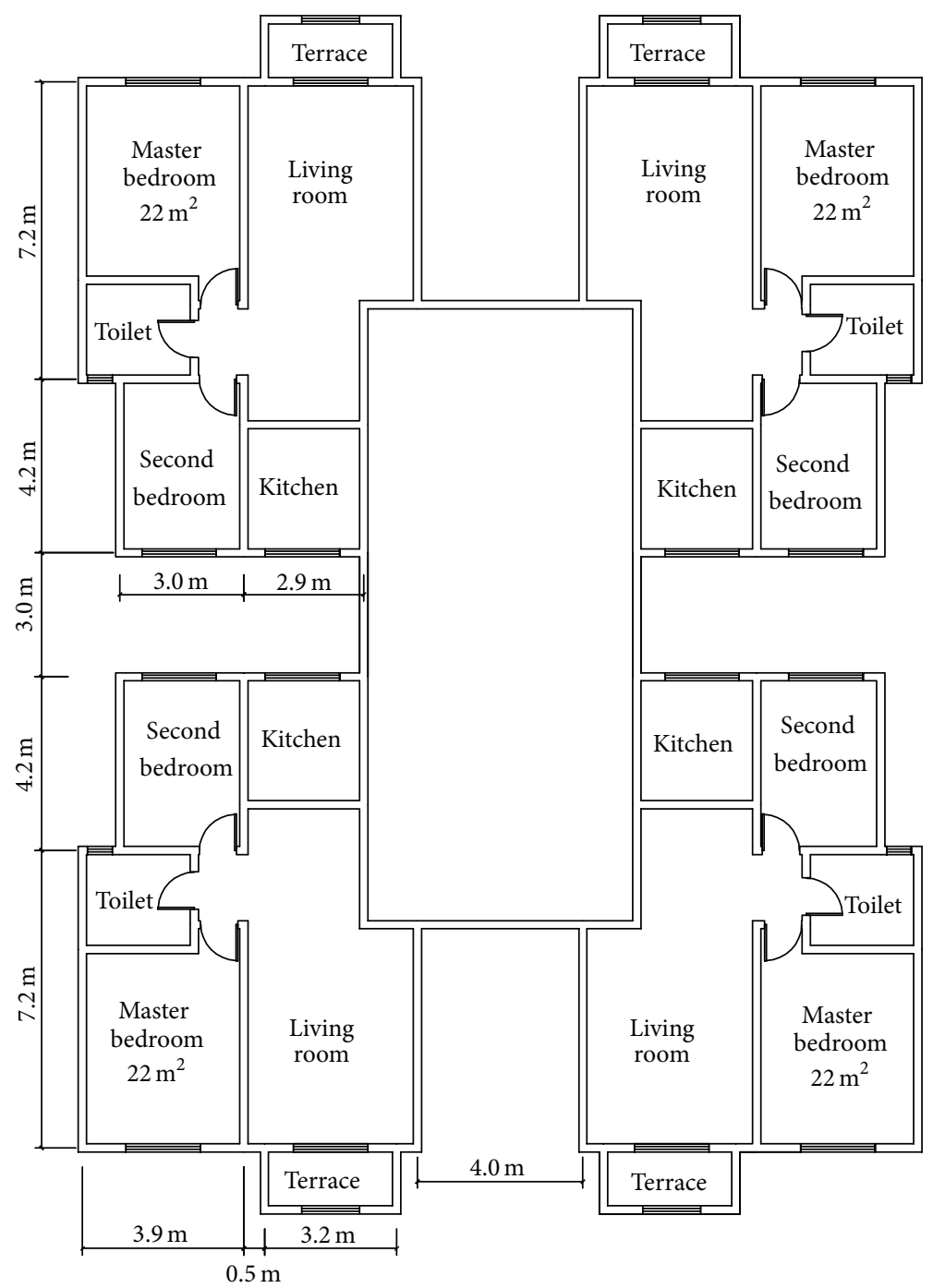

FigURE 8: Planar graph for residential floor plan.

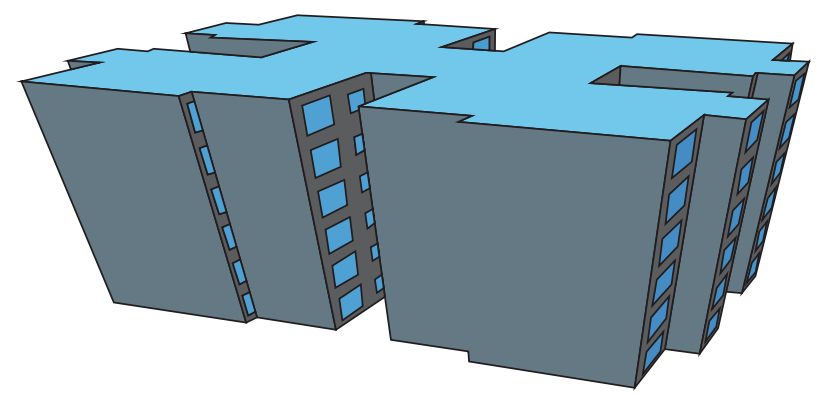

FIgURE 9: Simulated building model in DeST.

TABLE 2: Features of the glazing systems.

\begin{tabular}{lccccccc}
\hline Glazing type & Composition & SHGC & $\begin{array}{c}\text { Solar } \\
\text { transmittance }\end{array}$ & Solar reflectance & $\begin{array}{c}\text { Visible light } \\
\text { transmittance }\end{array}$ & $\begin{array}{c}\text { Visible light } \\
\text { reflectance }\end{array}$ & $\begin{array}{c}\text { Heat transfer } \\
\text { coefficients } \\
\left(\mathrm{W} /\left(\mathrm{m}^{2} \cdot \mathrm{K}\right)\right)\end{array}$ \\
\hline Hollow glass & $6 / 9 / 6$ & 0.722 & $51 \%$ & $11 \%$ & $63 \%$ & $13 \%$ & 3.100 \\
\hline Low- $E$ glass & $\begin{array}{c}6 \\
(\text { Low }-E) / 9 / 6\end{array}$ & 0.426 & $33 \%$ & $26 \%$ & $51 \%$ & $23 \%$ & 2.100 \\
\hline
\end{tabular}



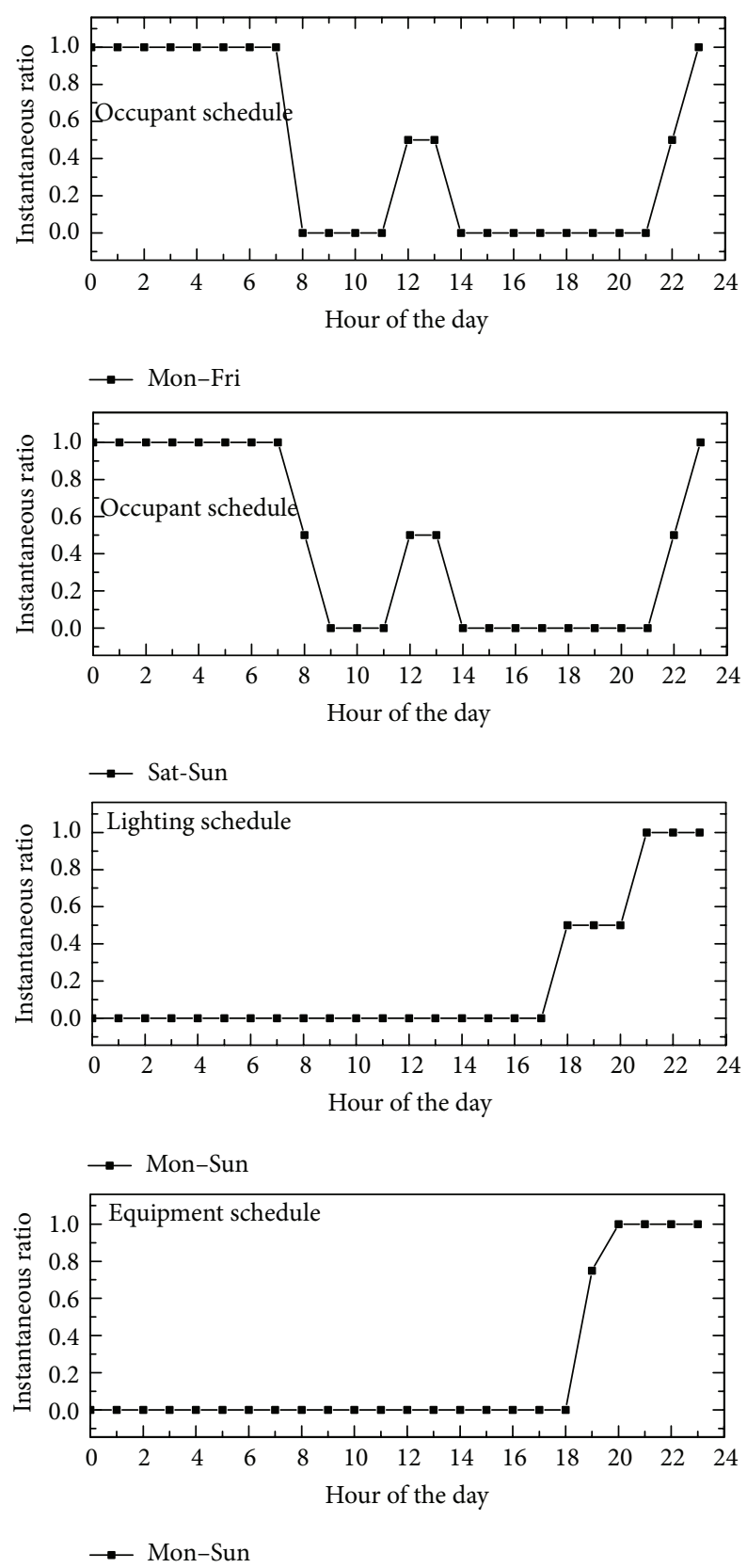

FIGURE 10: Schedules setting for occupant, lighting, and equipment.

TABLE 3: Window-wall ratios of each room and each orientation.

\begin{tabular}{lccccc}
\hline & South & North & East, west & Toilet & Kitchen \\
\hline Window-wall ratio & 0.5 & 0.45 & 0.3 & 0.18 & 0.4 \\
\hline
\end{tabular}

and annual cooling energy demand and total energy consumption change in an almost linear trend.

(2) In Chongqing, the change rate of annual heating energy demand, annual cooling energy demand, and total energy consumption with the windowwall ratio in the B3 is higher than in the B2 and $\mathrm{B} 1$. It could be concluded that minimizing the window-wall ratio in the operation mode of $\mathrm{B} 3$ has better energy saving effect than in the other two. When the external window faces are at the different orientations, the annual heating energy demand, annual cooling energy demand, and total energy consumption change in a similar pattern. They increase in a linear way with the increase of window-wall ratio, respectively. Nevertheless, the effect of the different orientations influencing energy consumption varies. But in Shanghai and Wuhan, the rate of change in annual heating energy demand, annual cooling energy demand, and total energy consumption remains stable when window-wall ratio 
TABLE 4: Other parameters of the building.

\begin{tabular}{lc}
\hline \multicolumn{2}{c}{ Other parameter settings } \\
\hline $\begin{array}{l}\text { Lighting thermal disturbance }\left(\mathrm{W} / \mathrm{m}^{2}\right) \\
\text { Equipment thermal disturbance in the }\end{array}$ & 5 \\
bedroom $\left(\mathrm{W} / \mathrm{m}^{2}\right)$ & 12.7 \\
$\begin{array}{l}\text { Equipment thermal disturbance in the } \\
\text { living room }\left(\mathrm{W} / \mathrm{m}^{2}\right)\end{array}$ & 9.3 \\
Cooling temperature set point $\left({ }^{\circ} \mathrm{C}\right)$ & 26 \\
Heating temperature set point $\left({ }^{\circ} \mathrm{C}\right)$ & 18 \\
EER & 2.3 \\
COP & 1.9 \\
Cooling season & May 1 to September 30 \\
Heating season & December 1 to February 28 \\
\hline
\end{tabular}

increases in different operation mode. The reduction of window-wall ratio has almost the same effect on energy efficiency for all the three operation modes in Shanghai and Wuhan.

(3) In Chongqing, when in the same operation mode, the annual heating energy demand appears to be the greatest when the window faces north, followed by when facing the east, west, and south. For the annual cooling energy demand and total energy consumption, the maximum is when facing west, followed by when facing the east, south, and north. In Shanghai, under the same operation mode conditions, the annual heating energy demand decreases slightly when the window faces north, west, east, and south. The annual cooling energy demand is greater when it faces east and west and smaller for north and south. For the total energy consumption, the order appears to be west, east, north, and south. However, in Wuhan, under the conditions with similar operation mode, there is a slight decrease in annual heating energy demand when the window faces north, west, east, and south, and the annual cooling energy demand and total energy consumption would be notable when facing east and west and smaller for north and south.

(4) In Chongqing, when the glazing of external window is hollow glass and Low- $E$ glass, the annual heating energy demand, annual cooling energy demand, and total energy consumption change with the windowwall ratio are parallel: all of them show a linear trend when the window-wall ratio increases. However, in Shanghai and Wuhan, when the glazing of external window is hollow glass and Low- $E$ glass, the trends of annual heating energy demand appear to be stable with the increase in window-wall ratio, while showing a linear trend in the annual cooling energy demand and total energy consumption.

5.3. Comparisons between the Different Cities. SHGC is by definition the fraction of external solar radiation that is admitted through a window, both directly transmitted, and absorbed and subsequently released inward. The lower the
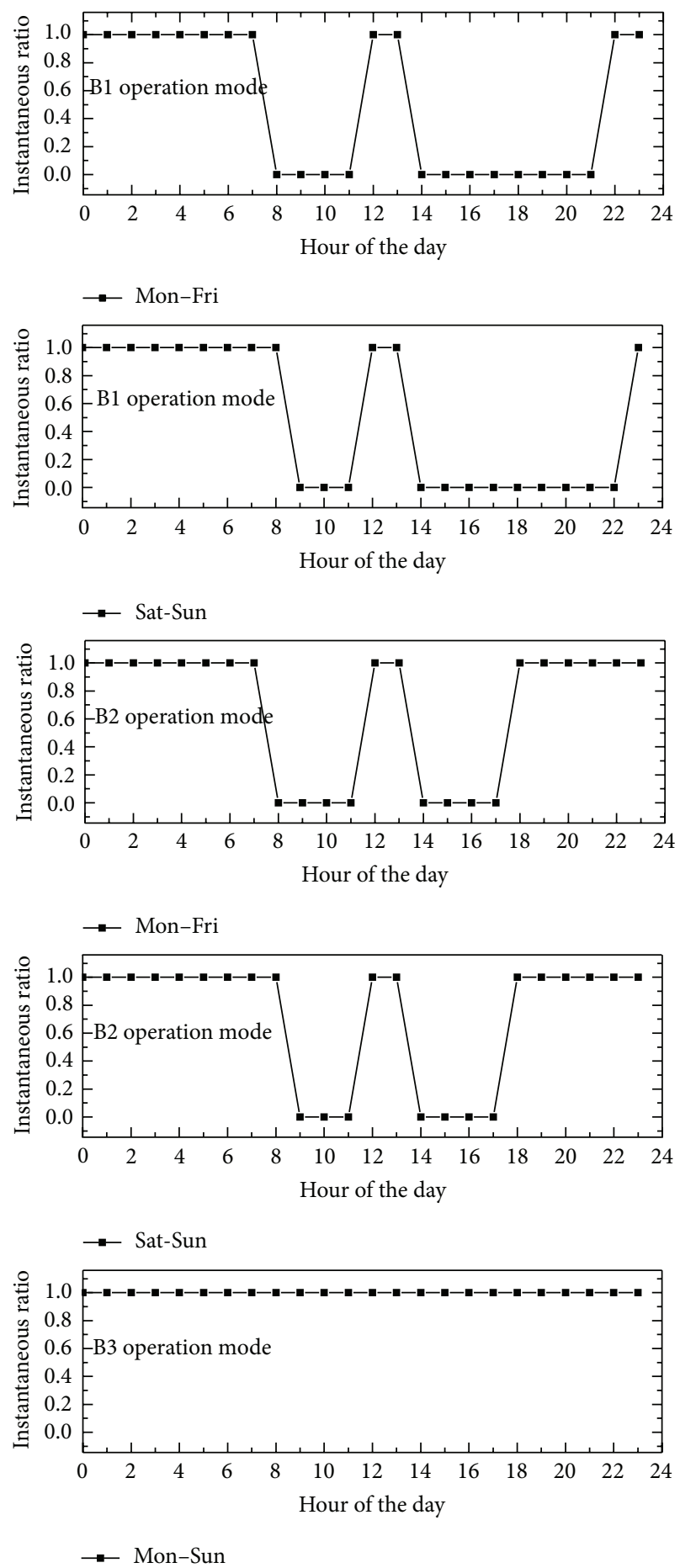

FIgURE 11: Schedules setting for air conditioning.

window's SHGC is, the less the solar heat it transmits. According to ISO 15099 standard [24], SHGC of a window is the result of the contribution of all the components, as

$$
\mathrm{SHGC}=\frac{\sum g_{g} A_{g}+\sum g_{r} A_{r}}{A_{W}} .
$$


TABLE 5: Air conditioning operation modes and external window of the bedroom.

\begin{tabular}{lcc}
\hline Code & B1 & B2 \\
\hline & Mon-Fri 12:00 a.m.-1:00 p.m., & Mon-Fri 12:00 a.m. $-1: 00$ p.m., \\
Air conditioning operation modes & 6:00 p.m.-7:00 a.m. \\
& Sat-Sun 12:00 a.m.-1:00 p.m., & Sat-Sun 12:00 a.m. $-1: 00$ p.m., \\
Code & 11:00 p.m.-8:00 a.m. & p.m.-8:00 a.m. \\
\hline Type of external windows & C1 & C 24 hours \\
\hline
\end{tabular}
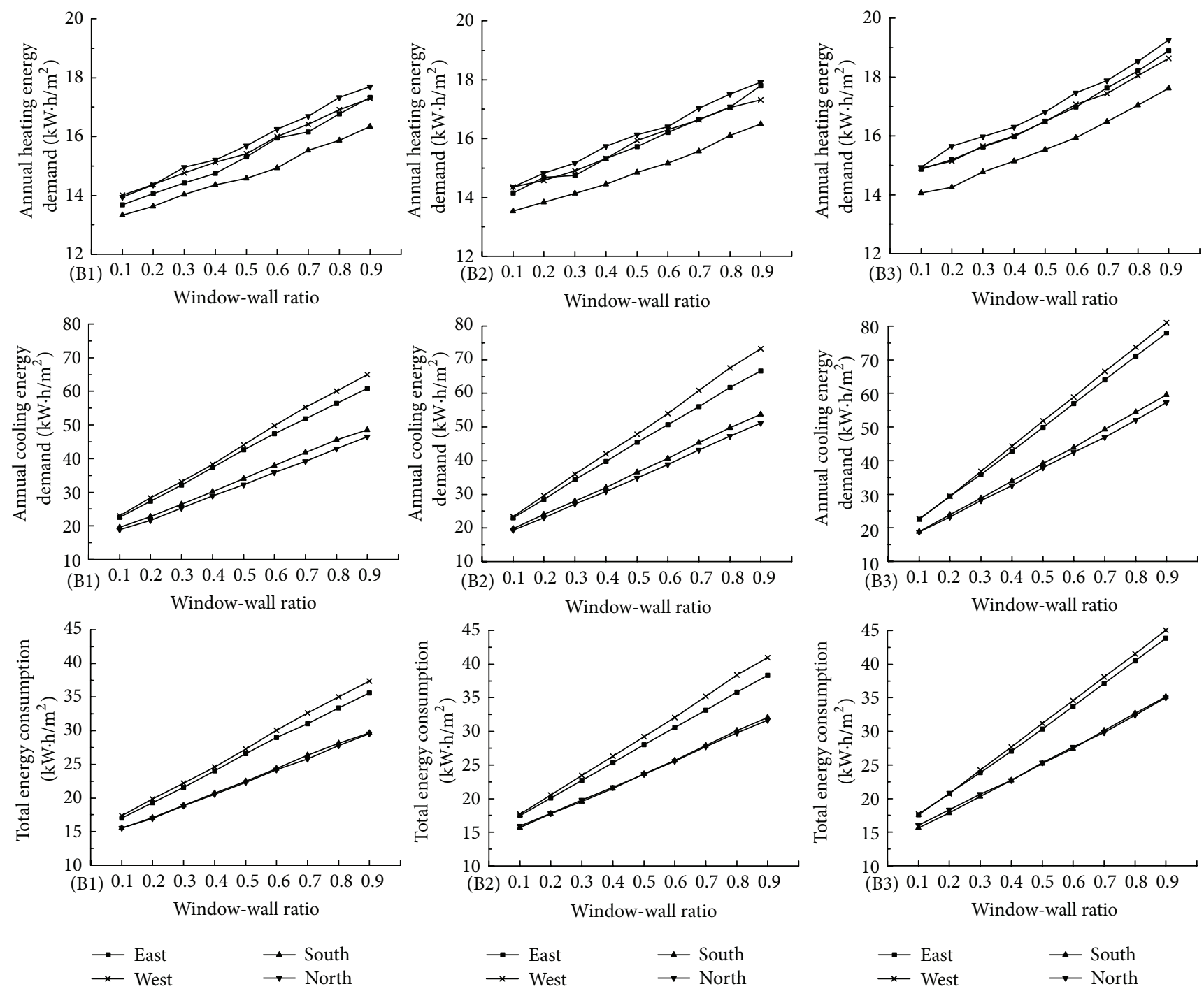

FIGURE 12: Relationship between energy consumption and window-wall ratio using hollow glass in Chongqing.

Buildings in hot summer and cold winter zone have no direct solar radiation on the north throughout the year; therefore, no solar radiation heat gain was obtained through the north window. Yet, the increase in window-wall ratio would result in the expansion of thermal transfer by different temperature, and consequently the annual heating energy demand of the bedroom increases. The increase of windowwall ratio of the bedroom leads to greater solar radiation heat gain through external window than the heat loss through the window. However, when the window-wall ratio increases beyond a critical value, the heat loss through the window would be greater than the solar radiation heat gain. Therefore, at first the annual heating energy demand decreases with the increase of window-wall ratio and then increases, but without an obvious trend.

The rate of change in annual cooling energy demand and total energy consumption with window-wall ratio is greater than annual heating energy demand. This is mainly because 

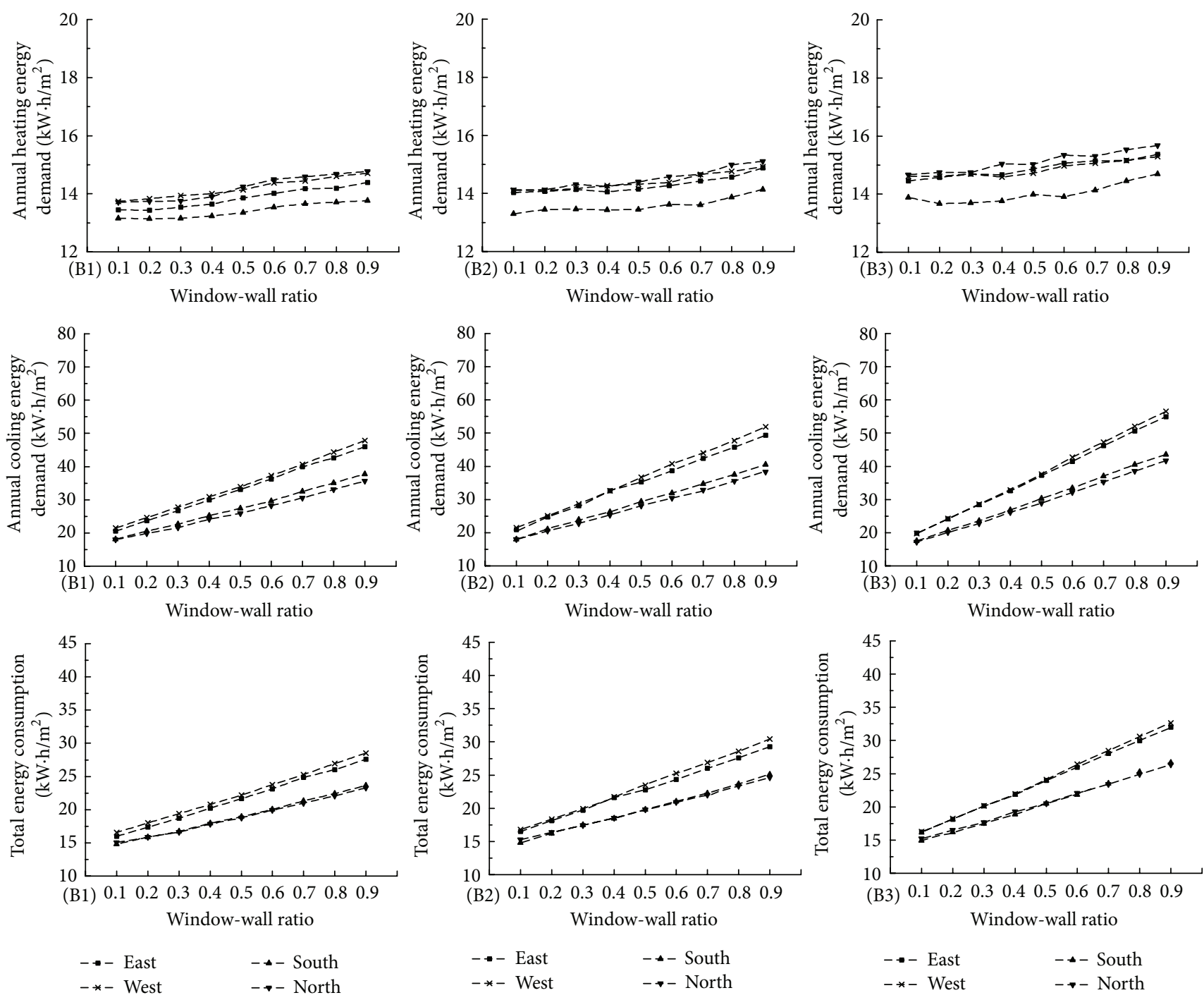

FIGURE 13: Relationship between energy consumption and window-wall ratio using Low-E glass in Chongqing.

both the indoor and outdoor temperature difference and solar radiation affect the heat gain in summer. The increase in window-wall ratio leads to dramatic increase in heat gain resulting from thermal transfer by differ temperature and solar radiation. However, the effect of heat gain from thermal transfer by differ temperature counteracts that of solar radiation in winter. As a result, the changing rate of annual cooling energy demand is at a higher level than that of annual heating energy demand. Meanwhile, in hot summer and cold winter zone, the absolute value of annual cooling energy demand is much higher than that of annual heating energy demand. Therefore, changing of window-wall ratio has a greater influence on annual cooling energy demand as well as the total energy consumption.

Windows facing west and east contribute to the highest total energy consumption, followed by windows facing the south and north. The solar radiation in Chongqing mainly is characterized by scattering, where the amount of direct sunlight is relatively smaller. Hence, it has a little influence on window orientations. On the other hand, the amount of direct solar radiation is larger in Shanghai and Wuhan than Chongqing. Therefore, the window-wall ratio of external windows in different orientations in Shanghai and Wuhan shows a clear difference: the impacts are higher when the window is facing the east or west than those facing the north or south. Besides, for all the three cities, the solar radiation on the east and west in summer is more intensive than that in winter, which increases the cooling load in summer through the external window. Moreover, solar radiation through the glass facing the west would be absorbed by the inside wall and the floor and then released later at night. The solar radiation in the glass facing the south in winter is more than that in summer and the solar radiation heat gain is relatively higher in winter, which is a benefit for the reduction of the annual heating energy demand consumption, while the solar radiation heat gain is relatively less in summer, which is a benefit for the reduction of the annual cooling energy demand consumption. Hence, the glazing area of windows 

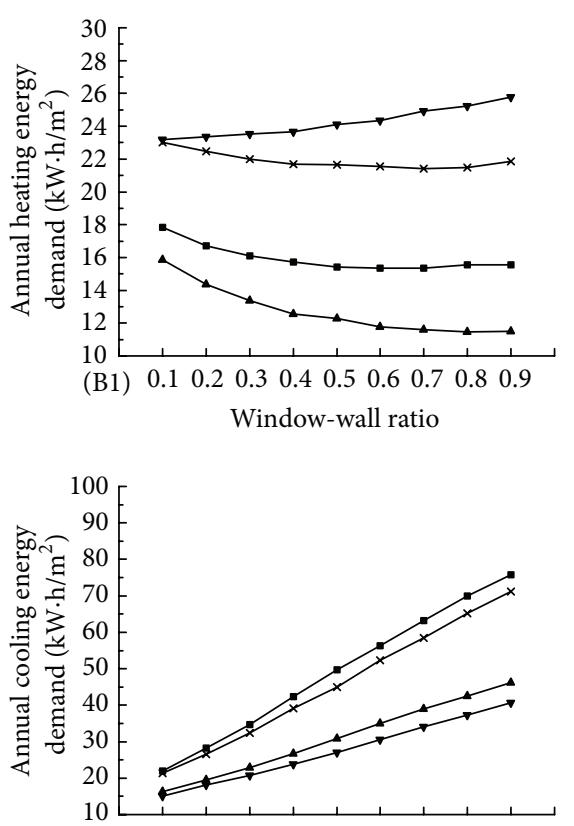

(B1) $0.1 \quad 0.2 \quad 0.3 \quad 0.4 \quad 0.5 \quad 0.6 \quad 0.7 \quad 0.8 \quad 0.9$

Window-wall ratio

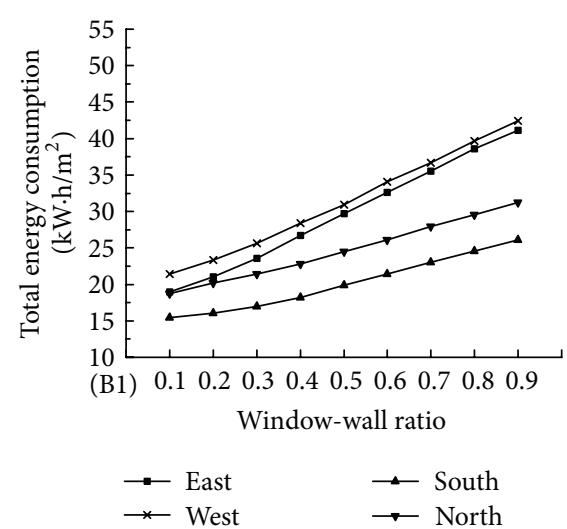

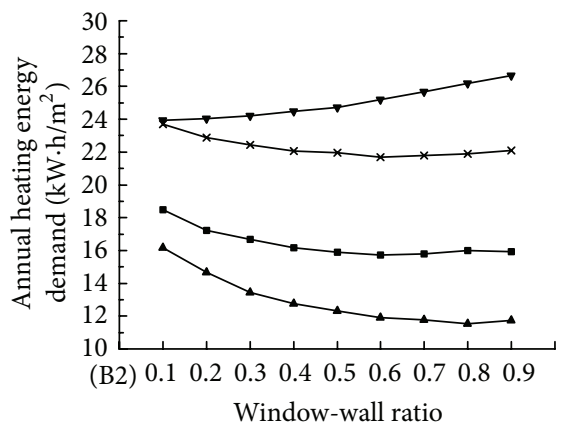

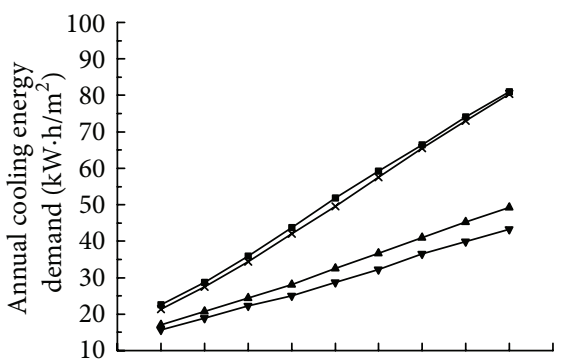

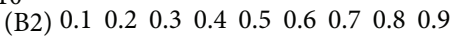

Window-wall ratio

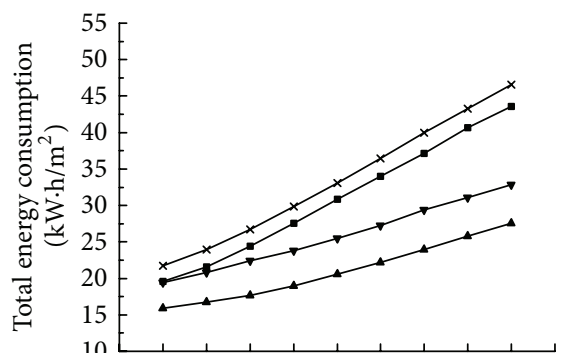

(B2) $0.10 .20 .3 \quad 0.40 .5 \quad 0.6 \quad 0.7 \quad 0.80 .9$

Window-wall ratio

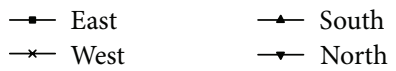

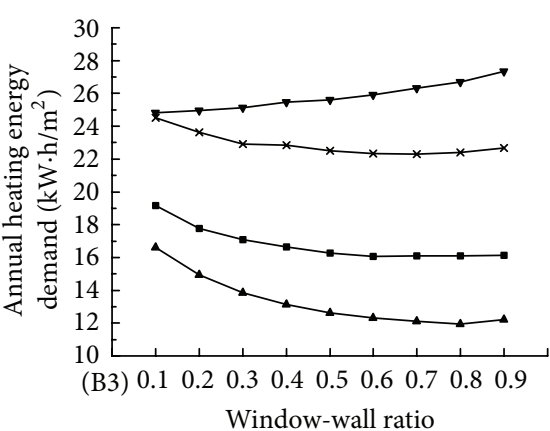
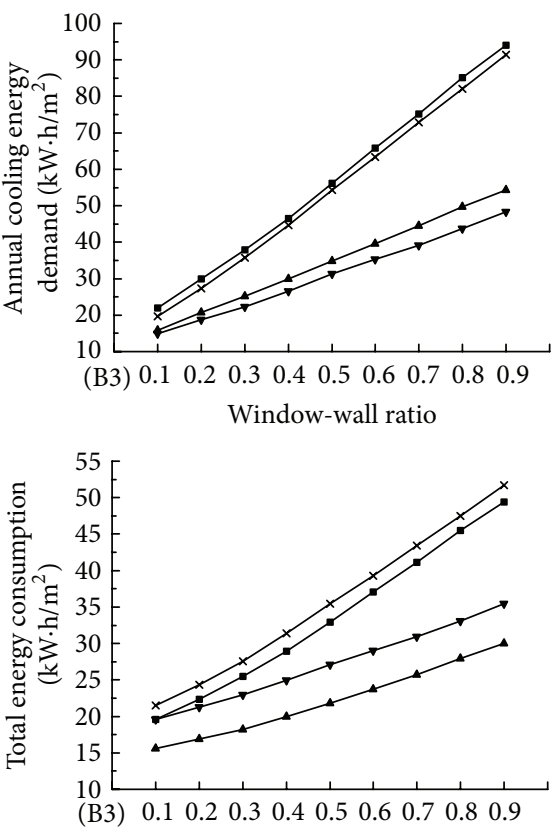

Window-wall ratio

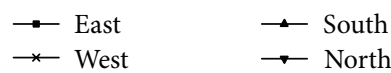

FIGURE 14: Relationship between energy consumption and window-wall ratio using hollow glass in Shanghai.

facing east or west should be carefully designed; that is, the window area should not be reduced at the cost of the performance of natural ventilation and lighting. Therefore, the windows of the bedroom can be placed on the north or south, and the effect of ventilation and lighting should be taken into consideration.

In addition, the annual energy consumption is less when the window is Low- $E$ glass compared to windows with hollow glass. This is determined by the property of low SHGC value of Low- $E$ glass. In summer, Low- $E$ glass may prevent the solar radiation and reduce the air conditioning cooling load. In winter, it can prevent radiation from inside through the glass and reduce the heating load. Furthermore, the heat transfer coefficient of Low- $E$ glass is lower than hollow glass; hence it can reduce the heat transfer though the bedroom external windows.

Based on the abovementioned discussions, the limited value of window-wall ratio and energy efficiency effect of Low- $E$ glass are suggested for bedroom external windows in typical cities in hot summer and cold winter zone and the result would play a critical role in designing the bedroom external windows. The limited value of bedroom external windows' window-wall ratio on the different orientations and the comparison of the effect of Low- $E$ glass on energy efficiency are shown in Figure 18. The comparison of the air conditioning operation mode is shown in Figure 19.

The result shows that, taking Chongqing as an example, when bedroom external window is facing east, the limited window-wall ratio is 0.4 and if the window-wall ratio is between 0.1 and 0.4 , there will be remarkable energy saving effect when Low- $E$ glass is used. Using B1 mode as a benchmark, under the same energy consumption level, when the window-wall ratio in $\mathrm{B} 1$ is 0.4 , the window-wall ratio of $\mathrm{B} 2$ and $\mathrm{B} 3$ should be 0.35 and 0.3 , respectively.

\section{Conclusions}

The study discussed the annual heating energy demand, annual cooling energy demand, and the total annual energy 

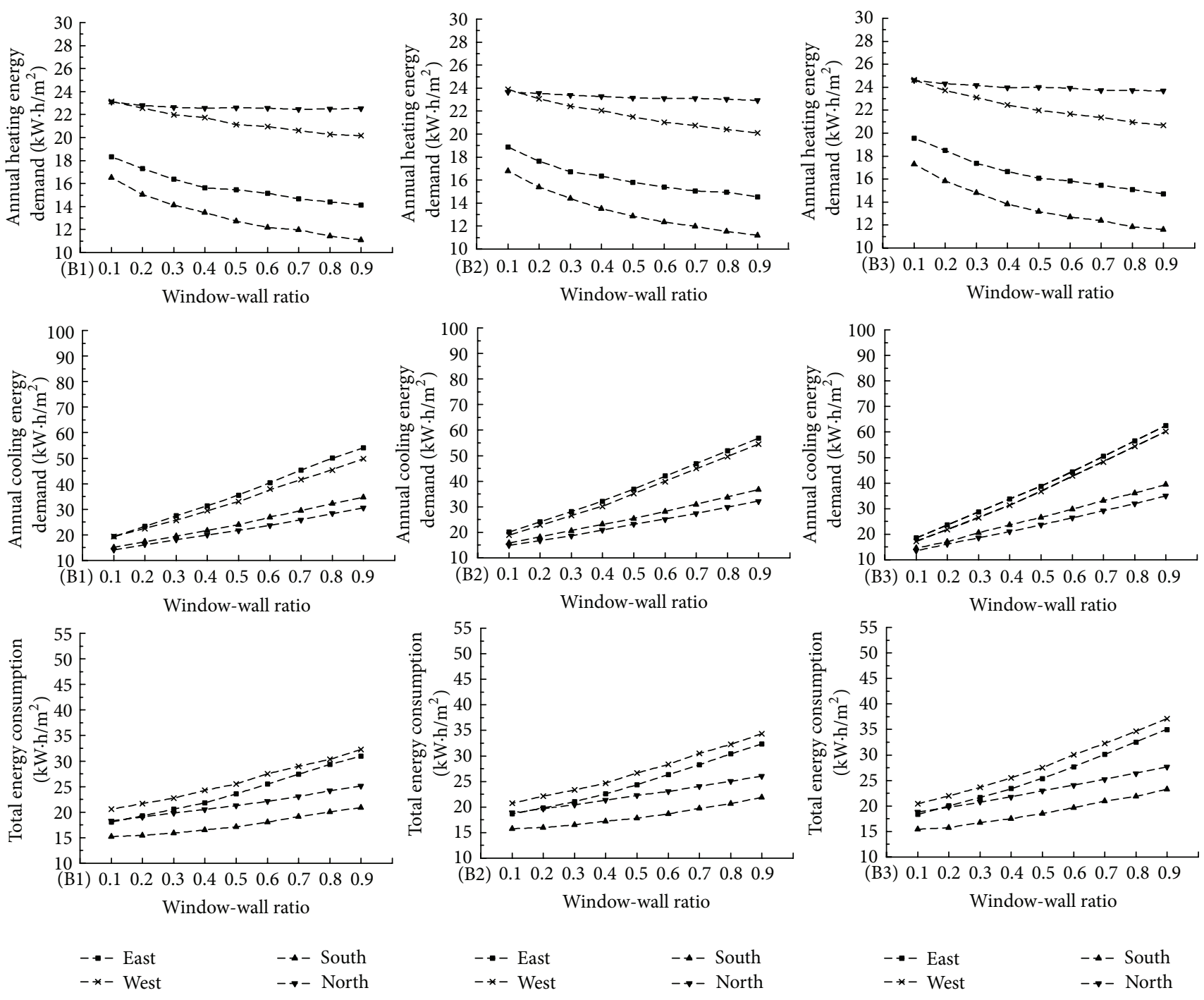

FIGURE 15: Relationship between energy consumption and window-wall ratio using Low- $E$ glass in Shanghai.

consumption at different conditions including different orientations, patterns of utilization, window-wall ratio, and types of windows in the three cities in hot summer and cold winter zone in China. Moreover, the impact of windowwall ratio and window material types on the air conditioning energy consumption is analyzed. The study shows the following:

(1) The change patterns of annual heating energy demand, annual cooling energy demand, and the total energy consumption under different air conditioning operation modes are almost consistent. For the operation modes of long service time, the energy saving effect for reducing window-wall ratio would be more significant.

(2) Windows facing the east and west contribute to the greater effect on the energy consumption of bedrooms. Windows facing east or west should be avoided or the window-wall ratio of them should be limited, and external windows with suitable shading coefficient should be applied or movable sun-shading for the windows should be set up. In consideration of the building energy efficiency design, the windows of bedrooms should be on the north façade or the south and ventilation and natural lighting need to be considered.

(3) Reducing the window-wall ratios of bedrooms in hot summer and cold winter zone would provide significant energy saving benefits. The energy efficiency performance would be significantly increased by reducing the window-wall ratio for external windows of hollow glass compared to when it is Low- $E$ glass.

(4) The design of external windows in Chongqing should control the window-wall ratio and comprehensively consider the ventilation and natural lighting. When the external window faces east or west, synthesis shading devices should be installed. 

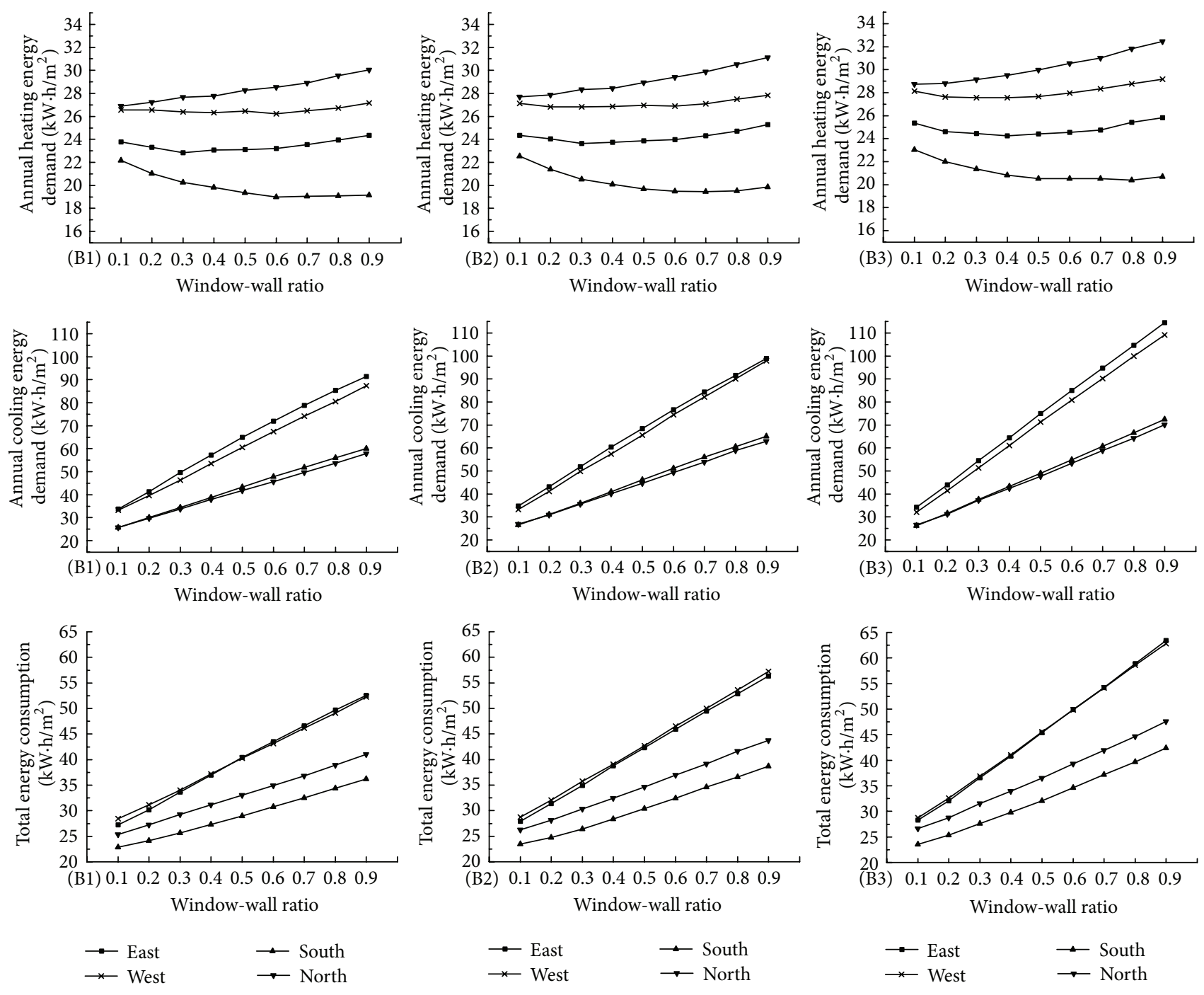

$\begin{array}{ll}\rightarrow \text { East } & \rightarrow \text { South } \\ * \text { West } & \rightarrow \text { North }\end{array}$

FIGURE 16: Relationship between energy consumption and window-wall ratio using hollow glass in Wuhan.

(5) For Shanghai and Wuhan, the window-wall ratio of bedroom external windows should be limited to 0.5 when the window faces north or south, while it should be 0.3 when facing east or west. Window-wall ratio can be increased properly if the material type of external window is Low-E glass of high reflectivity and low-emissivity.

In addition, the paper discussed how the occupants' patterns of behavior influence annual heating and cooling energy and presented that occupants' patterns of behavior should be taken into full account in building energy conservation design.

\section{Nomenclature}

$\alpha_{K}$ : Effective transmittance of interface $K$

$\beta_{K}$ : Forward direction effective reflectance of interface $K$
$\beta_{K}^{\prime}: \quad$ Reciprocal value of opposite direction effective reflectance of interface $K$

$\beta_{K+1}$ : $\quad$ Effective reflectance of the last interface

$\rho_{K}: \quad$ Reflectance of interface $K$

$\tau_{a, K \rightarrow K+1}$ : Transmittance of medium between interface $K$ and $K+1$

$\tau^{(N)}$ : $\quad$ Total transmittance of fenestration

$Q_{K \rightarrow K+1}$ : Radiation energy absorbed by medium between interface $K$ and $K+1$ (W)

$\zeta(K, K+1)$ : Radiation energy absorptivity of the medium to the first layer radiation energy input

$\zeta_{K \rightarrow K+1}: \quad$ Absorptivity of input radiation energy for interface $K$

$c_{p i}: \quad \quad$ Specific heat capacity of layer $i(\mathrm{~J} /(\mathrm{kg} \cdot \mathrm{K}))$

$\rho_{i}: \quad$ Density of layer $i\left(\mathrm{~kg} / \mathrm{m}^{3}\right)$

$\Delta x_{i}: \quad$ Thickness of layer $i(\mathrm{~m})$

$A_{g}: \quad$ The areas of glass $\left(\mathrm{m}^{2}\right)$

$A_{f}: \quad$ The areas of frame $\left(\mathrm{m}^{2}\right)$ 

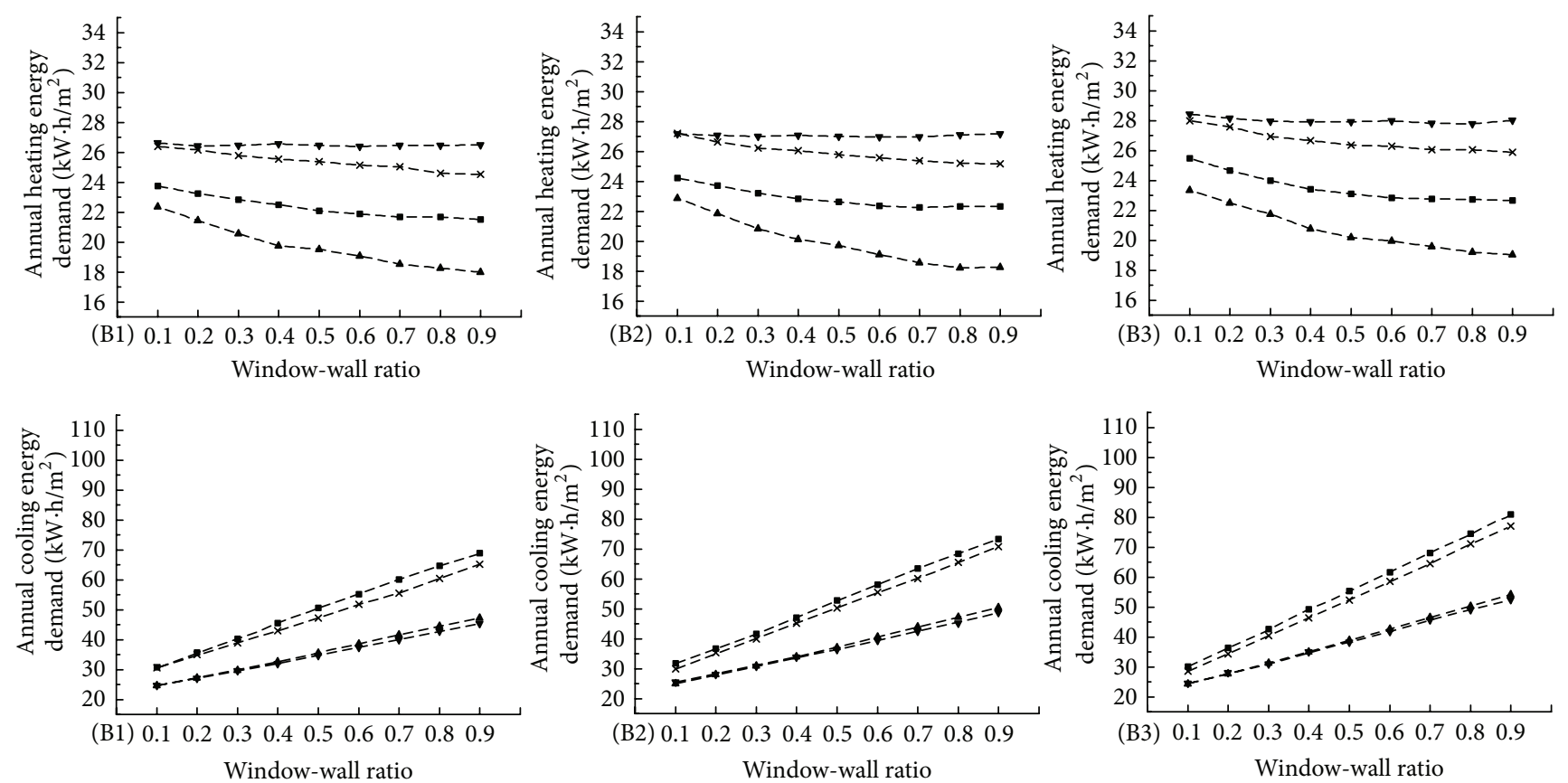

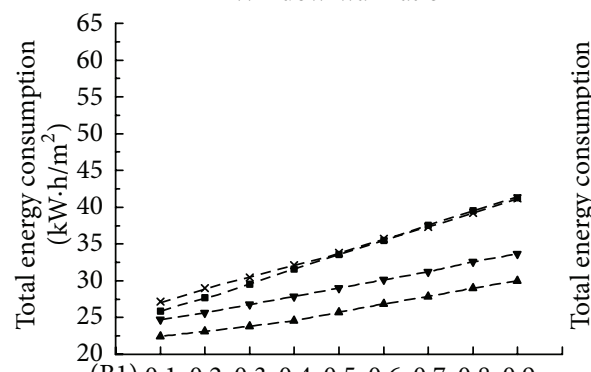

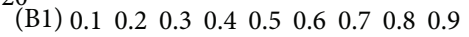
Window-wall ratio





- - East

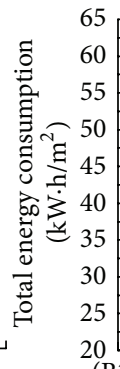

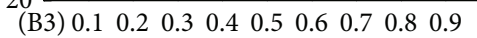
Window-wall ratio

$$
-- \text { East } \quad-\leadsto-\text { South }
$$

FIGURE 17: Relationship between energy consumption and window-wall ratio using Low- $E$ glass in Wuhan.

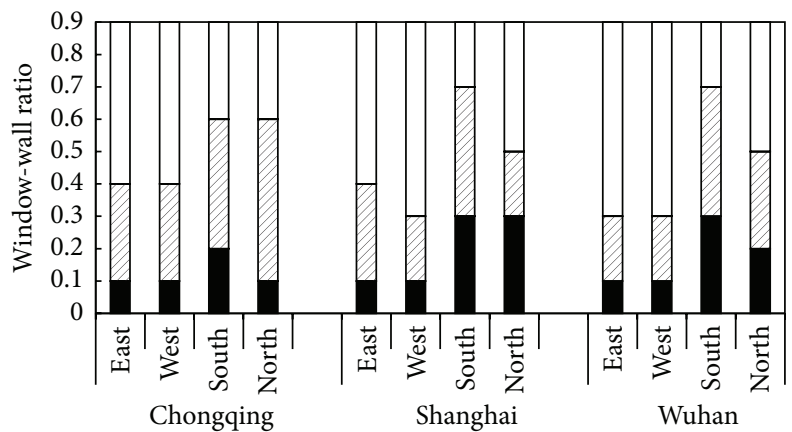

- Unremarkable energy saving effect

- Not recommended

๑ Remarkable energy saving effect

FIGURE 18: The proposed scope of window-wall ratio and the comparison of the effect of Low-E on energy efficiency on different orientations in Chongqing, Shanghai, and Wuhan. 


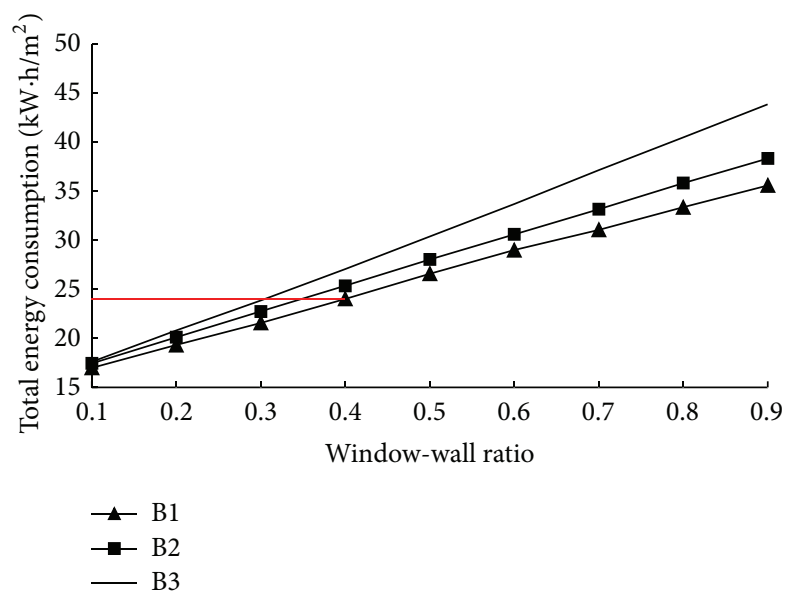

FIgURE 19: The comparison of the air conditioning operation mode in east orientation using hollow glass in Chongqing.

$A_{w}:$ The window total area $\left(\mathrm{m}^{2}\right)$

$E$ : $\quad$ Surface emissivity of glass surface

$F_{K}$ : Radiation energy converged by reflection part of $G_{K}$ and transmission part of $F_{K}^{\prime}$ (W)

$F_{K}^{\prime}$ : Radiation energy into the interface $K$ from the other side (W)

$g_{g}$ : Total solar transmittance values of the glass

$g_{f}$ : Total solar transmittance values of the frame

$G_{K}$ : Radiation energy into the interface $K$ from one side (W)

$G_{K}^{\prime}$ : Radiation energy converged by transmission part of $G_{K}$ and reflection part of $F_{K}^{\prime}(\mathrm{W})$

$G_{\text {adj }}$ : Ventilation quality with adjacent room $(\mathrm{kg} / \mathrm{s})$

$G_{o}$ : Ventilation mass exchange with ambient $(\mathrm{kg} / \mathrm{s})$

$G_{\mathrm{lw}}$ : Long wave radiation heat transfer between inner surfaces of building envelope (W)

$h_{r}$ : Radiation heat transfer coefficient of inner surface of building envelope $\left(\mathrm{W} /\left(\mathrm{m}^{2} \cdot \mathrm{K}\right)\right)$

$h_{\text {out }}$ : Heat transfer coefficient of outer surface of building envelope $\left(\mathrm{W} /\left(\mathrm{m}^{2} \cdot \mathrm{K}\right)\right)$

$h_{\text {in }}$ : Heat transfer coefficient of inner surface of building envelope $\left(\mathrm{W} /\left(\mathrm{m}^{2} \cdot \mathrm{K}\right)\right)$

$h_{r, o}$ : Radiation heat transfer coefficient of outer surface of building envelope $\left(\mathrm{W} /\left(\mathrm{m}^{2} \cdot \mathrm{K}\right)\right)$

$h_{1}$ : Heat transfer coefficient of inner glass surface $\left(\mathrm{W} /\left(\mathrm{m}^{2} \cdot \mathrm{K}\right)\right)$

$h_{3}$ : Heat transfer coefficient of outer glass surface $\left(\mathrm{W} /\left(\mathrm{m}^{2} \cdot \mathrm{K}\right)\right)$

$h_{i, j}$ : Comprehensive heat transfer coefficient between two adjacent glass surfaces, including heat transfer through air layer and long wave radiation between the two glass surfaces $\left(\mathrm{W} /\left(\mathrm{m}^{2} \cdot \mathrm{K}\right)\right)$ $h_{r 1, j}: \quad$ Radiation heat transfer coefficient between inner glass surface and its corresponding environment surface $\left(\mathrm{W} /\left(\mathrm{m}^{2} \cdot \mathrm{K}\right)\right)$

$h_{r 3, j}$ : Radiation heat transfer coefficient between outer glass surface and its corresponding environment surface $\left(\mathrm{W} /\left(\mathrm{m}^{2} \cdot \mathrm{K}\right)\right)$

$q_{1}$ : Window inner layer absorption of radiation energy $\left(\mathrm{W} / \mathrm{m}^{2}\right)$

$q_{2}$ : Window middle layer absorption of radiation energy $\left(\mathrm{W} / \mathrm{m}^{2}\right)$

$q_{3}$ : Window outer layer absorption of radiation energy $\left(\mathrm{W} / \mathrm{m}^{2}\right)$

$q_{1 \text {,rad }}$ : Window inner layer absorption of long wave radiation energy except the solar radiation $\left(\mathrm{W} / \mathrm{m}^{2}\right)$

$q_{3, \text { rad }}$ : Window outer layer absorption of long wave radiation energy except the solar radiation $\left(\mathrm{W} / \mathrm{m}^{2}\right)$

$Q_{s, r, w i}:$ Solar radiation absorbed by window $(\mathrm{W})$

$Q_{\text {occ }}$ : Quantity of heat from occupant (W)

$Q_{\text {equ }}$ : Quantity of heat from equipment (W)

$Q_{\text {adj,rad }}$ : Radiation heat from adjacent room (W)

$Q_{s, r, \text { wa }}$ : Solar radiation absorbed by wall (W)

$Q_{s, \text { tr: }}: \quad$ Transmission solar radiation (W)

$Q_{\mathrm{li}}: \quad$ Quantity of heat from lighting (W)

$Q_{\text {hvac }}$ : Quantity of heat from HVAC (W)

$R_{i, j, a}$ : Heat transfer resistance of air between two adjacent glass surfaces $\left(\mathrm{m}^{2} \cdot \mathrm{K} / \mathrm{W}\right)$

$R_{i, j, \mathrm{lvr}}$ : Heat transfer resistance of long wave radiation between two adjacent glass surfaces $\left(\mathrm{m}^{2} \cdot \mathrm{K} / \mathrm{W}\right)$

$t_{o}: \quad$ Outdoor air temperature $\left({ }^{\circ} \mathrm{C}\right)$

$t_{\text {adj }}: \quad$ Adjacent room air temperature $\left({ }^{\circ} \mathrm{C}\right)$

$t_{\text {env }}: \quad$ Environment temperature $\left({ }^{\circ} \mathrm{C}\right)$

$t_{\text {gro }}$ : The underground soil temperature $\left({ }^{\circ} \mathrm{C}\right)$

$t_{1}$ : $\quad$ Temperature of window inner layer $\left({ }^{\circ} \mathrm{C}\right)$

$t_{2}$ : Temperature of window middle layer $\left({ }^{\circ} \mathrm{C}\right)$

$t_{3}$ : $\quad$ Temperature of window outer layer $\left({ }^{\circ} \mathrm{C}\right)$

$t_{1, a}$ : Air temperature in the $t_{1}$ 's immediate vicinity $\left({ }^{\circ} \mathrm{C}\right)$

$t_{3, a}: \quad$ Air temperature in the $t_{3}$ 's immediate vicinity $\left({ }^{\circ} \mathrm{C}\right)$

$t_{1, j}$ : Temperature of environment surface corresponding to inner glass surface $\left({ }^{\circ} \mathrm{C}\right)$

$t_{3, j}$ : Temperature of environment surface corresponding to outer glass surface $\left({ }^{\circ} \mathrm{C}\right)$

$T: \quad$ Thermodynamic temperature of glass surface $(\mathrm{K})$.

\section{Conflict of Interests}

The authors declare that there is no conflict of interests regarding the publication of this paper.

\section{Acknowledgment}

The authors would like to appreciate the support from the project funded by National Key R\&D Programme of China's 12th Five-Year Plan (2013BAJ11B05). 


\section{References}

[1] A. Maccari and M. Zinzi, "Simplified algorithms for the Italian energy rating scheme for fenestration in residential buildings," Solar Energy, vol. 69, pp. 75-92, 2000.

[2] China Academy of Building Research, JGJ134-2010. Design Standard for Energy Efficiency of Residential Buildings in Hot Summer and Cold Winter Zone, China Architecture \& Building Press, Beijing, China, 2010, (Chinese).

[3] Y. B. Hou and X. Z. Fu, "Affection of window-wall ratio on energy consumption in region of hot summer and cold winter," Architecture Technology, vol. 32, pp. 661-662, 2002 (Chinese).

[4] Y. W. Jian and Y. Jiang, "Influence of WWR on annual energy consumption for heating and air conditioning in residential buildings," Heating Ventilating and Air Conditioning, vol. 36, pp. 1-5, 2006 (Chinese).

[5] Y. Feng and H. Yang, "Defining the area ratio of window to wall in 'design standard for energy-efficiency of residential buildings in hot summer and cold winter zone", Journal of Xian University of Architecture \& Technology, vol. 33, pp. 348-351, 2001 (Chinese).

[6] H. H. Wang, G. Rui, and Q. L. Xiao, "Energy saving effect of building envelope in summer," Journal of Central South University of Technology (English Edition), vol. 19, no. 5, pp. 1370-1376, 2012.

[7] M. N. Inanici and F. N. Demirbilek, "Thermal performance optimization of building aspect ratio and south window size in five cities having different climatic characteristics of Turkey," Building and Environment, vol. 35, no. 1, pp. 41-52, 2000.

[8] H. S. Li, Y. Gao, G. J. Zhao, and Y. Z. Jing, "Impact of window-wall ratio on air conditioning energy consumption under different residential using modes in Guangzhou," Applied Mechanics and Materials, vol. 316-317, pp. 1123-1127, 2013.

[9] Z. Zhou, S. Hu, and T. Du, "Study on determination of best window-wall ratio of office building in cold area," Applied Mechanics and Materials, vol. 261-262, pp. 209-216, 2013.

[10] Z. Yu, W. L. Zhang, and T. Y. Fang, "Impact of building orientation and window-wall ratio on the office building energy consumption," Applied Mechanics and Materials, vol. 409-410, pp. 606-611, 2013.

[11] F. Goia, M. Haase, and M. Perino, "Optimizing the configuration of a façade module for office buildings by means of integrated thermal and lighting simulations in a total energy perspective," Applied Energy, vol. 108, pp. 515-527, 2013.

[12] J. W. Lee, H. J. Jung, J. Y. Park, J. B. Lee, and Y. Yoon, "Optimization of building window system in Asian regions by analyzing solar heat gain and daylighting elements," Renewable Energy, vol. 50, pp. 522-531, 2013.

[13] S.-H. Kim, S.-S. Kim, K.-W. Kim, and Y.-H. Cho, "A study on the proposes of energy analysis indicator by the window elements of office buildings in Korea," Energy and Buildings, vol. 73, pp. 153-165, 2014.

[14] M. S. Al-Homoud, "Optimum thermal design of office buildings," International Journal of Energy Research, vol. 21, no. 10, pp. 941-957, 1997.

[15] K. J. Kontoleon and D. K. Bikas, "Modeling the influence of glazed openings percentage and type of glazing on the thermal zone behavior," Energy and Buildings, vol. 34, no. 4, pp. 389-399, 2002.

[16] C. A. Johnson, R. W. Besant, and G. J. Schoenau, "Economic preferred window orientation and optimum fenestration design of a non-daylit and daylit large office building for different climate conditions and different billing structures," ASHRAE Transactions, vol. 96, pp. 23-33, 1990.

[17] X. Su and X. Zhang, "Environmental performance optimization of window-wall ratio for different window type in hot summer and cold winter zone in China based on life cycle assessment," Energy and Buildings, vol. 42, no. 2, pp. 198-202, 2010.

[18] C. Tian, T. Chen, H. Yang, and T.-M. Chung, "A generalized window energy rating system for typical office buildings," Solar Energy, vol. 84, no. 7, pp. 1232-1243, 2010.

[19] C. E. Ochoa, M. B. C. Aries, E. J. van Loenen, and J. L. M. Hensen, "Considerations on design optimization criteria for windows providing low energy consumption and high visual comfort," Applied Energy, vol. 95, pp. 238-245, 2012.

[20] D. Yan, X. Xie, F. Song, and Y. Jiang, "Building environment design simulation soft-ware DeST (1): an overview of developments and information of building simulation and DeST," Journal of HV\&AC, vol. 34, no. 7, pp. 48-56, 2004 (Chinese).

[21] W. Q. Gao, R. H. Ye, and Y. R. He, Optics, Nanjing University, Beijing, China, 2000, (Chinese).

[22] S. M. Yang and W. Q. Tao, Heat Transfer, Higher Education Press, Beijing, China, 1998, (Chinese).

[23] Ministry of Housing and Urban-Rural Development of the People's Republic of China, "Thermal design code for civil building," Tech. Rep. GB50176-93, China Planning Press, Beijing, China, 1993.

[24] ISO (International Organization for Standardization), Thermal Performance of Windows, Doors and Shading Devices-Detailed Calculations, ISO 15099, ISO (International Organization for Standardization), 2003. 

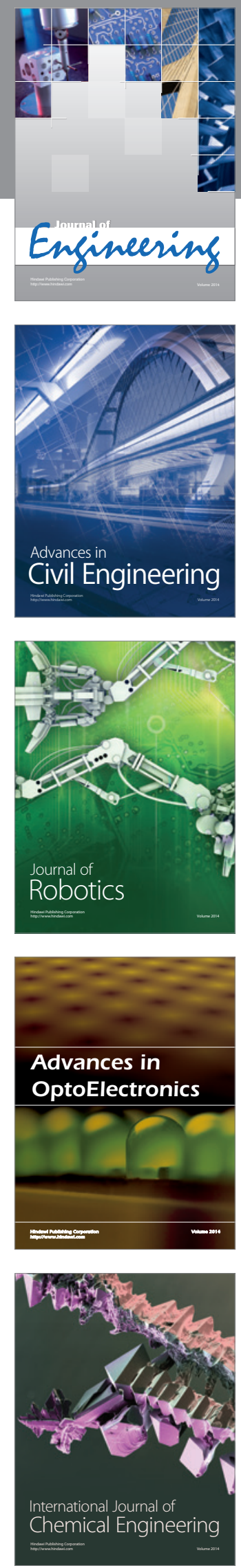

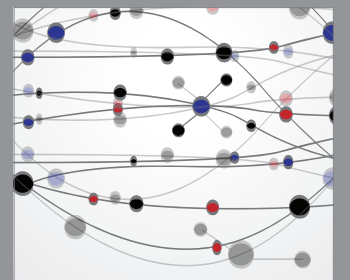

The Scientific World Journal
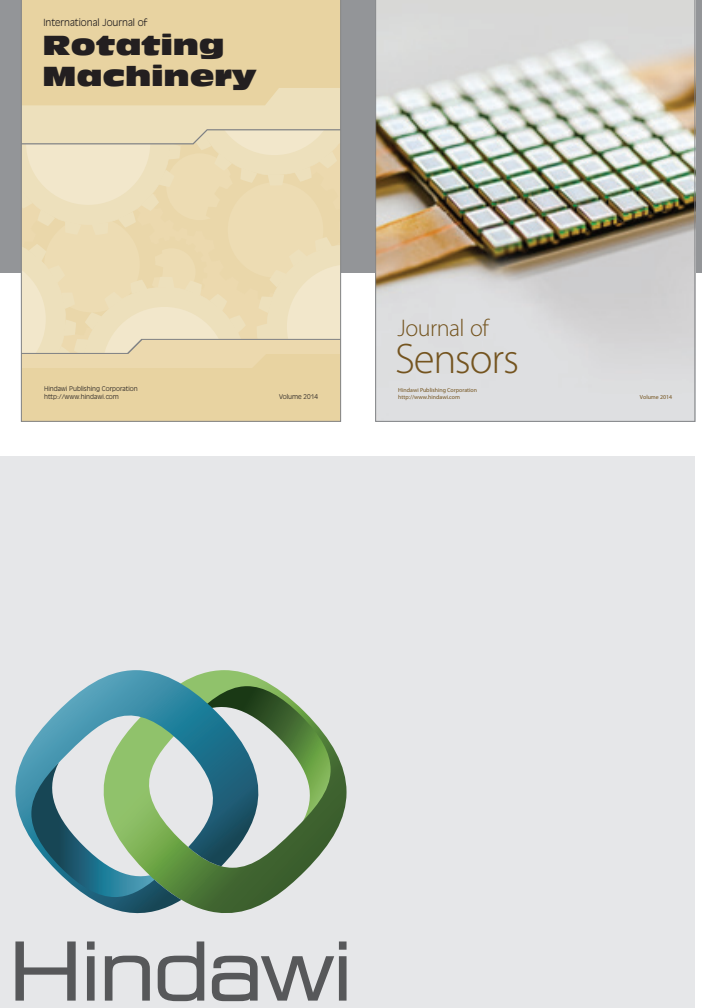

Submit your manuscripts at http://www.hindawi.com
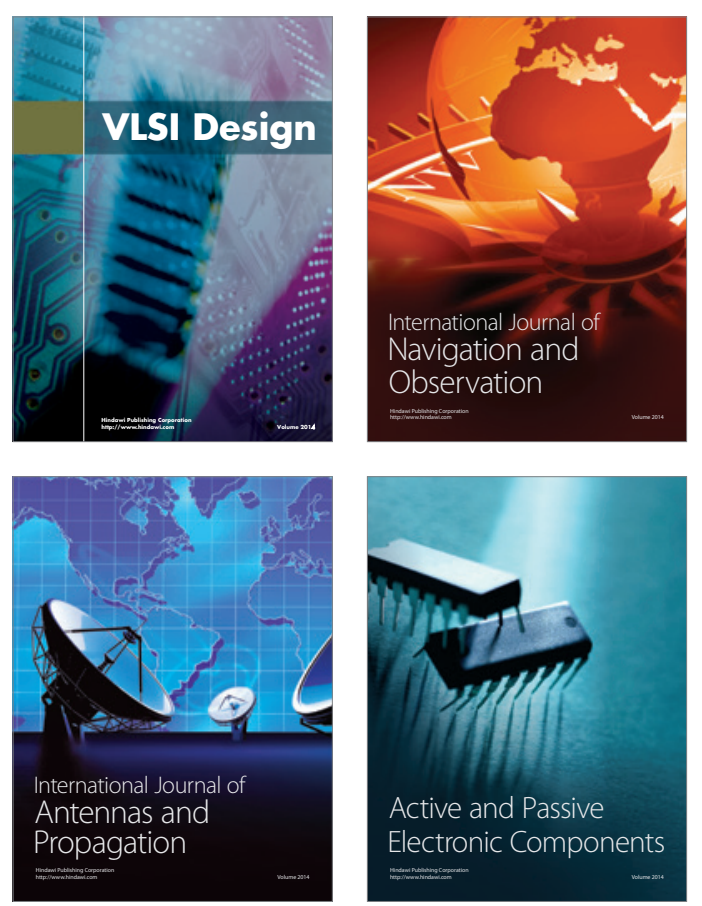


Journal of

Control Science

and Engineering
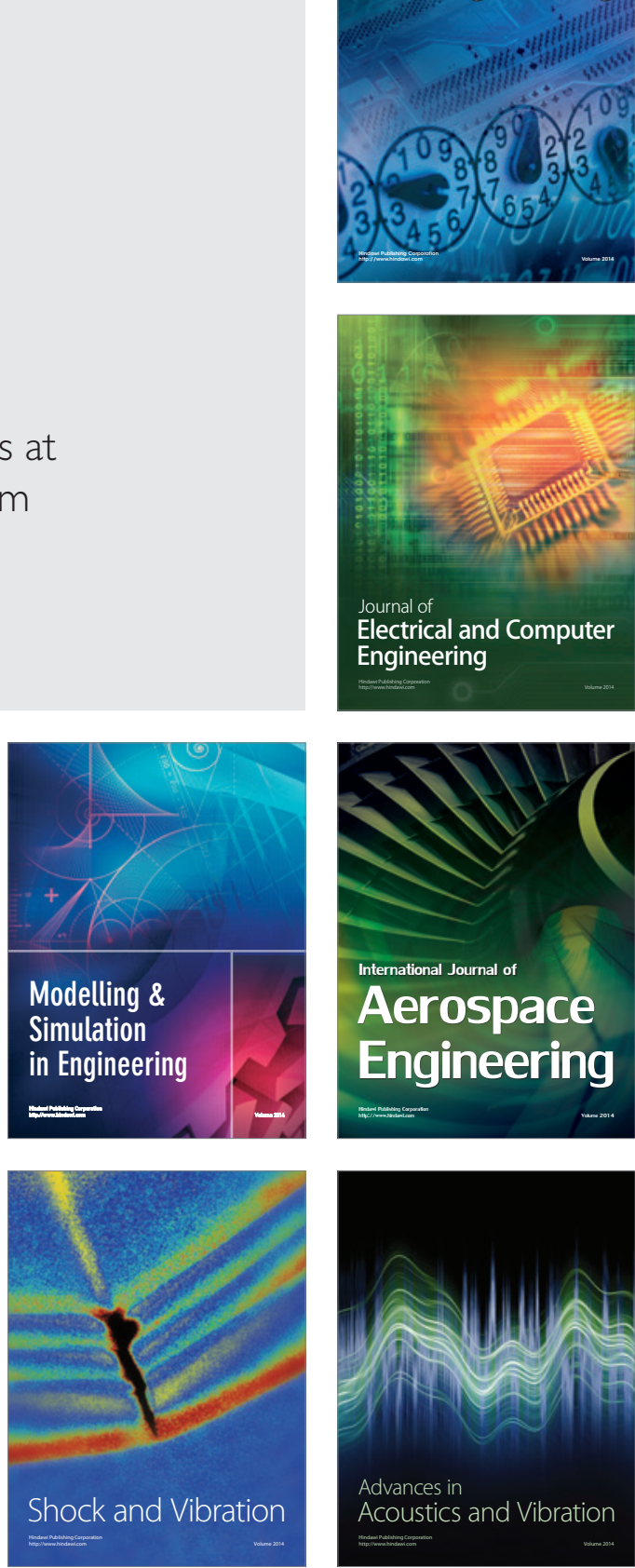